\title{
THE POSSIBLE EFFECT OF FLAXSEED EXTRACT ON LETROZOLE-INDUCED POLYCYSTIC OVARY RAT MODEL: CORRELATIVE HISTOLOGICAL AND FUNCTIONAL STUDY
}

\author{
By \\ Mona Mohamed Abd El-Galil ${ }^{\text {** }}$ and Shaymaa Fathy Mohammed ${ }^{\mathrm{b}}$ \\ ${ }^{\mathrm{a}}$ Histology and Cell Biology Department, Faculty of Medicine (Girls), Al-Azhar \\ University, 11651, Cairo, Egypt \\ bPhysiology Department, Faculty of Medicine (Girls), Al-Azhar University, 11651, Cairo, \\ Egypt \\ *Corresponding author: Mona Mohamed Abd El-Galil \\ Mobile: (+2) 01090305671, E-mail: medicalmona2009@yahoo.com \\ ORCID: 0000-0002-8837-5717 \\ Institutional e-mail address: mona.elsayed@azhar.edu.eg \\ Authors e-mail addresses: shaymaa_selem@yahoo.com \\ Mobile: (+2) 01140758888 \\ Institutional email address: Shaymaa.Fathy@azhar.edu.eg
}

\begin{abstract}
Background: Polycystic Ovary Syndrome (PCOS) is one of the most common metabolic disorders affecting women in the reproductive age leading to infertility/subfertility. It may occur as a complication of Letrozole (LTZ) therapy in breast cancer patients.

Objective: This was a preliminary study to assess the possible protective and/or curative effect of flaxseed extract in a letrozole-induced PCO rat model.

Material and Methods: Thirty-six adult female albino rats were divided into five main groups: Group I kept as the control group, Group II (Letrozole-induced PCO group), received letrozole solution ( $3 \mathrm{mg} / \mathrm{kg}$ ) orally once daily by gastric tube for 21 days. Group III (combined flaxseed and letrozole group), received aqueous flaxseed extract ( $500 \mathrm{mg} / \mathrm{kg} /$ day) orally one hour before letrozole in the same dose and duration as group II, Group IV (recovery group), received letrozole in the same dose and duration as group II and then left without treatment for the next 4 weeks after PCO induction, Group V (flaxseed-treated group), treated with aqueous flaxseed extract orally once daily for the next 4 weeks after PCO induction. At the end of the experiment, final body weight, ovarian weight, blood glucose, serum antioxidants assay, and sex hormones levels were measured. Also, specimens of ovaries were processed for light and electron microscopic studies. Histomorphometric and statistical analyses were done.

Results: letrozole-induced PCO resulted in a significant increase in final body weight, ovarian weight as well as abnormal blood glucose, sex steroids hormone levels, and antioxidant assays. Moreover, numerous ovarian cystic follicles, widespread cytoplasmic vacuolation in the granulosa lutein cells, congested blood capillaries, and increased fibrosis within the ovarian medulla were evident in the PCO group in concomitant with a significant increase in area percentage of collagen fibers. The ultrastructural assessment confirmed these distortions. The protective and curative potential of flaxseed is mostly comparable revealed improvement in
\end{abstract}




\section{MONA M. ABD EL-GALIL AND SHYMAA FATHY MOHAMED}

the final body weight, biochemical markers and histological changes, with the protective effect was more pronounced than the curative one.

Conclusion and Recommendation: Flaxseed succeeded in ameliorating letrozole-induced polycystic ovary owing to its phytochemicals, antioxidant and anti-inflammatory properties with folliculogenesis potentials. So, it is recommended to use flaxseed as a co-therapy with letrozole to reduce its hyperandrogenic effects.

Keywords: Letrozole; Flaxseed; polycystic ovary; ultrastructure; antioxidant; rat.

\section{INTRODUCTION}

Polycystic ovary syndrome (PCOS) is characterized by infrequent or absent menses, miscarriage, dysfunction of follicular maturation, anovulation and signs of hyperandrogenism including acne or seborrhea, and hirsutism leading to infertility/subfertility (Sirmans and Pate, 2013). Classical morphology of PCOS includes multiple tiny capsular follicular cysts, luteinized inner theca, stromal hyperplasia, many atretic and immature follicles, which indicate cessation of folliculogenesis (Dewailly et al., 2014). Long term consequences include increased risk of endometrial cancer, insulin resistance diabetes mellitus (DM), dyslipidemia, hypertension, and cardiovascular disorders (Ghafurniyan et al., 2015).

Several endocrine disorders enhance and intensify each other in PCOS. These disorders include hypothalamic-pituitarygonad (HPG) axis dysfunction that ends in abnormal gonadotropin secretion and increased secretion of ovarian steroids thereby preferentially promoting androgen synthesis. The level of estrogen progenitors, i.e. testosterone and androstenedione, is increased, as well (Legro et al., 2013). National Institutes of Health postulates that higher concentrations of androgens in blood and/or clinical hyperandrogenism are the key criteria for PCOS diagnosis (Conway et al., 2014).
Letrozole is a potent and highly specific nonsteroidal aromatase inhibitor that competitively binds to the heme of the cytochrome P450 subunit, an enzyme responsible for the rate-limiting step in estrogen biosynthesis, leading to a nearcomplete blockade of the aromatization in peripheral tissues without exerting effects on other steroidogenic pathways (Elliott et al., 2014). letrozole has emerged as a promising therapeutic agent to ameliorate certain gynecologic disorders, expanding its indications for use in the treatment of some hormone receptor-positive dependent diseases in premenopausal women, such as endometriosis and uterine fibroids (Stubert et al., 2014).

However, studies have demonstrated an increase in ovarian weight and number of cystic follicles together with interstitial cell hyperplasia, ovarian hyperandrogenism in letrozole exposed adult female rats, meeting the morphologic criteria for polycystic ovary syndrome (Dewailly et al., 2014).

To date, no single medication exists for PCOS. It tailors according to the symptoms. Currently, many medications are in use to manage anovulation but have been reported to cause severe side effects and psychological disturbances (EscobarMorreale, 2018).

Herbal remedies widely received attention as a form of lifestyle management in traditional medicine. 
Flavonoids are plant-based compounds of great interest because of their expansive pharmacological activities which valuable in decreasing oxidative stress and lipid peroxidation with minimal or no side effects (Rizwan et al., 2014).

Flaxseed or linseed (Linium Usitatissimum L) is an annual or biannual herb that belongs to the Linaceae family and is mostly used as an edible herb in different countries. Flaxseed is an essential source of high-quality protein and soluble fiber. It contains approximately $6 \%$ moisture, essential fatty acids including the alpha-linolenic acid (ALA), a biologic precursor of omega-3 fatty acids, linoleic acid, an omega- 6 fatty acid, and omega- 9 essential fatty acids in perfect balance which provides most of the benefits of flaxseed oil (Ganorkar and Jain, 2013). Also, it contains A, B, D and E vitamins, potassium, lecithin, magnesium, $6 \%$ mucilage, and small amounts of linamarin, a cyanogenic glycoside (McCann et al., 2014).

Flaxseed is emerging as one of the key sources of phytochemicals (phenolic acids, cinnamic acids, flavonoids, and lignins). The most important lignan in flaxseed is secoisolariciresinol diglucoside (SDG) that is converted to the active biological form (enterodiol and enterolactone) by the effect of beneficial intestinal bacteria which is a weaker estrogen, compared to endogenous estradiol. Flaxseed contains 700-800 times more lignans than any other plant. lignans have antioxidant, anti-angiogenic, antiviral, antifungal, and antiinflammatory non-hormonal properties which affect cell growth and viability
(Cetisli et al., 2015). So, many nutritional, physiological, biochemical, and pharmacological researches focused on the health properties of flaxseed in controlling many chronic disorders like cardiovascular diseases, strokes, cancers, DM and treatment of women's diseases (Jangale et al., 2016).

Consequently, this experimental study was designed to assess the probable protective and/or curative role of flaxseed extract against letrozole-induced PCOS in adult female albino rats.

\section{MATERIALS AND METHODS}

\section{Animals:}

Thirty-six non-pregnant adult female Wistar albino rats of a local strain weighing $180 \pm 20 \mathrm{~g}$ and aged approximately $12-16$ weeks with regular estrus cycles (following 3 cycles checking), were chosen for the current study. Rats were purchased from Helwan breeding farm, Helwan, Egypt. Animals were settled under normal laboratory conditions with a room temperature of 25 $\pm 2^{\circ} \mathrm{C}$, the humidity of $(54 \pm 5 \%)$ and alternating light/dark cycles in conventional clean properly ventilated wire-mesh cages $(25 \times 30 \times 25 \mathrm{~cm}-3$ rats per cage) at the animal house, Faculty of Medicine (Girls), Al-Azhar University, Cairo, Egypt. Rats were acclimated for one week for adaptation before beginning the experiment. They were fed on a normal chow diet and allowed free access to water throughout the experiment. All the ethical protocols for the experimental use of laboratory animals were carried out after approval of the Faculty of Medicine (Girls) Institutional Research Board (FMG-IRB), Al-Azhar University, Cairo, 


\section{MONA M. ABD EL-GALIL AND SHYMAA FATHY MOHAMED}

Egypt. All rats were selected in the estrous phase based on the vaginal smears. The estrous phase was identified by the presence of large cornified epithelial cells arranged in clumps (Figure 1).

\section{Drugs and chemicals:}

Letrozole: A commercially available formulation (Femmara ${ }^{\circledR}$ ) was purchased from Novartis pharmaceutical AG Company, Switzerland. It was provided in $2.5 \mathrm{mg}$ scored tablet. Six tablets were crushed, was dissolved in $30 \mathrm{ml}$ of $0.5 \%$ carboxymethyl cellulose (CMC), and $1 \mathrm{ml}$ of the prepared solution $(0.5 \mathrm{mg} / \mathrm{ml})$ was given to the rats by oro-gastric tube at a therapeutic dose of $3 \mathrm{mg} / \mathrm{kg} / \mathrm{day}$, for 3weeks (Elliott et al., 2014 and Stubert et al., 2014).

Flaxseed (Linum Usitatissimum) extract: A commercially available flaxseed was purchased from local markets as a pouch of 250 grams of organic brown flaxseeds with a brand name Markal (Part number: GRALBC250, Markal, Snacks). The crude extract was obtained from, Nawah scientific center, Cairo, Egypt.

\section{Flaxseeds extract preparation:}

The crude extract of flaxseed was prepared through the conventional solvent extraction process. Flaxseeds were completely ground into powder in a grinder (B-400, Buchi Labortechnik AG, Switzerland). About 100 grams of the flaxseeds powder was soaked in 2 liters of $70 \%$ aqueous methanol solution in a sealed glass container for about 5 days. The supernatant was separated and the remaining plant material was again soaked in $70 \%$ aqueous methanol solution for another 5 days. The filtrates for the two collections were concentrated by using a rotary evaporator under reduced pressure at $50 \mathrm{C}$ and dried in a bath of warm water to get the crude extract. The resultant semi-solid extract was put into a lyophilizer machine for $24 \mathrm{~h}$ to make a powder following the methods of Ho et al. (2007) and Ahmad et al. (2012). $540 \mathrm{mg}$ of the powder was dissolved in $6 \mathrm{ml}$ distilled water (DW), then $1 \mathrm{ml}$ of the aqueous solution $(90 \mathrm{mg} / \mathrm{ml})$ was given by gastric intubation in a daily dose equivalent to $500 \mathrm{mg} / \mathrm{kg}$ (MalekMohammadi et al., 2015 and Sulaiman et al., 2015).

\section{Experimental design:}

Rats were randomly dispensed into five groups:

- Group I (control group): Twelve adult female albino rats were subdivided equally into two subgroups: subgroup IA received equivalent volume $(1 \mathrm{ml})$ of $\mathrm{DW}$ and subgroup IB received $1 \mathrm{ml}$ of $0.5 \%$ CMC (Letrozole vehicle) orally once daily for 21 consecutive days and then rats were sacrificed.

- Group II (Letrozole-induced PCO group): Six adult female albino rats received $1 \mathrm{ml}$ of the prepared letrozole solution $(0.5 \mathrm{mg} / \mathrm{ml})$ orally at a dose of $3 \mathrm{mg} / \mathrm{kg} / \mathrm{rat}$ by gastric gavage, once daily in the early morning for 21 consecutive days and then they were sacrificed.

- Group III (combined flaxseed and letrozole group): Six rats received aqueous flaxseed extract $(90 \mathrm{mg} / \mathrm{ml})$ orally at a dose of $(500 \mathrm{mg} / \mathrm{kg} /$ day $)$ one hour before oral administration of 
letrozole solution by the same dose and duration as group II.

- Group IV (Recovery group): Six rats received letrozole solution by the same dose and duration and then were left spontaneously with no further treatment till the end of the experiment (4 weeks), and then they were sacrificed.

- Group V (Flaxseed-treated group): Six rats received letrozole solution by the same dose and duration as group II, and then received aqueous flaxseed extract by the same dose as group III along with basal diet daily for the next 4 weeks and then rats were sacrificed.

All rats were weighed individually at the beginning of the experimental protocol, and at the end, just before collecting samples.

\section{Vaginal Smear Collection:}

The swab smear technique was applied in which the animals were kept immobile and lightly gripping the tail. A moistened cotton bud swab (approximately $5 \mathrm{~mm}$ wide and $12 \mathrm{~mm}$ long) imbibed in normal saline $(\mathrm{NaCl} 0.9 \%)$ was inserted into the vagina to a depth of approximately $1.0 \mathrm{~cm}$ with a rotating action of the swab in the same direction, gently removing the cells from the vaginal lumen and walls. The tip of the swab was rolled gently onto clean glass slides in a thin layer (smear) and allowed to air dry. The swab stick was discarded, a new one being used for each animal. A different glass slide was used for each animal in each cage of the different experimental groups. The dry fixed slides were then stained metachromaticaly by using Toluidine blue stain, then examined by light microscopy for proper orientation of the estrous cycle according to the proportion of observed cells in the smears (Cora et al., 2015 and Jafarey \& Jaffri, 2016).

Blood glucose was measured weekly using a glucometer (SD Code free blood glucose monitoring system, SD Biosensor, INC., Korea).

At the end of the experiment, animals were overnight fasted, blood samples were withdrawn from retro-orbital sinuses by capillary tubes under ether anesthesia, centrifuged at 3000 round per minute to separate the serum that was maintained in a freezer at $-80^{\circ} \mathrm{C}$ until further analyses for antioxidants activity assay including total antioxidant capacity (TAC) and malondialdehyde (MDA). Tumor necrotic factor-alpha (TNF- $\alpha$ ) was also assessed (Liao et al., 2012). TAC was estimated by the conventional colorimetric method using Quanti Chrom TM assay kits (Biodiagnostic Company, Egypt) according to the manufacturer's instruction (Malek-Mohammadi et al., 2015). The levels of tumor necrotic factoralpha (TNF- $\alpha$ ) were determined using a rat-specific, commercially available enzyme-linked immunosorbent assay (ELISA) kit (BioSource International Inc., California, USA) according to the manufacturer's instructions (Kafi et al., 2015). Results of TNF- $\alpha$ were expressed as $\mathrm{pg} / \mathrm{ml}$, while those of TAC and MDA were expressed as $\mathrm{mMol} / \mathrm{L}$ and $\mathrm{ng} / \mathrm{L}$, respectively. Sex hormones including follicle-stimulating hormone (FSH), Luteinizing hormone (LH), estradiol (E2), progesterone, and testosterone levels were measured in serum by the ELISA method using a rat kit (Accu-Bind, Monobind ELIZA Microwells .Inc., Lake Forest, CA 


\section{MONA M. ABD EL-GALIL AND SHYMAA FATHY MOHAMED}

CA (92630) USA) (Kheirabad et al., 2016). These biochemical studies were done in El Nour Global Lab, Cairo, Egypt.

A midline incision was done on the anterior aspect of the abdomen, and the right ovary samples were excised, weighed, and processed for light and electron microscopic examination.

\section{Preparation of specimens for light microscopic studies:}

Samples from the right ovary were immediately fixed in $10 \%$ buffered formalin for 72 hours, dehydrated in ascending grades of ethyl alcohol, followed by clearance in xylene, impregnation and embedding in paraffin wax to obtain paraffin blocks. Sections of $5 \mu \mathrm{m}$ thickness were cut using a rotary microtome (LEICA RM 2125; UK), mounted on clean glass slides, and stained with the following (Bancroft \& Layton, 2013):

1. Hematoxylin and Eosin (H\&E) stain for studying the general histological structure.

2. Masson's Trichrome stain for staining the collagen fibers.

\section{Preparation of specimens for transmission electron microscopic (TEM) studies:}

Small pieces of left ovary were trimmed into approximately $0.5 \mathrm{~mm} 3$, and immediately fixed in $2.5 \%$ phosphatebuffered glutaraldehyde in 0.1 sodium phosphate buffer ( $\mathrm{pH} 7.2)$, post-fixed with $1 \%$ phosphate-buffered osmium tetroxide, rinsed in distilled water followed by dehydration in ascending grades of ethanol. Afterward, specimens were embedded in epoxy resin and allowed to polymerize overnight at $60{ }^{\circ} \mathrm{C}$. Following polymerization, semithin sections were cut at $1 \mu \mathrm{m}$ thickness using the ultramicrotome, stained with $1 \%$ Toluidine blue, examined by light microscopy for proper orientation. Ultrathin sections (80$90 \mathrm{~nm}$ ) were stained with uranyl acetate and lead citrate and examined and photographed by transmission electron microscope (JEOL JEM-100; Tokyo, Japan) (Hayat, 2000 and Golomb et al., 2012). This study was done in the electron microscope research unit, Regional Center for Mycology and Biotechnology (RCMB), AL-Azhar University, Egypt.

\section{Histo-morphometric measurements:}

All sections were examined, photographed by Leica DM2500 optical microscopes (Leica microsystems, Nussloch, Germany) coupled to a Leica ICC50 W digital camera, and transferred to the screen using a computerized image analyzer Leica Q500 MC program (Leica Microsystems Ltd, Cambridge, UK). The data were calibrated automatically to convert the measurement units (pixels) produced by the image analyzer program into actual micrometer units. Ten different non-overlapping randomly selected fields from five different ovarian sections in each group, were examined to quantitatively evaluate the following:

- The numbers of ovarian follicles (/field) including primordial, primary, preantral, antral, cystic follicles and corpora lutea in $H \& E$ stained section at X 100 magnification on every 10th section of the ovary. So, each section was separated by a distance of approximately $50-60 \mu \mathrm{m}$ so that follicles were not repeated (Atilgan et al., 2015). 
- The thickness of granulosa and theca interna cell layer $(\mu \mathrm{m})$ of antral and cystic follicles at X 200 magnification (Medigović et al., 2012 and Shaaban et al., 2018).

- The mean area percentage of the green stained collagen fibers $/ \mu \mathrm{m} 2$ within the ovarian medulla in Masson trichromestained sections at $\times 100$ magnification (Atilgan et al., 2015).

All histomorphometric measurements were carried out at the Regional Center for Mycology and Biotechnology (RCMB), Al-Azhar University, Cairo, Egypt.

\section{Statistical Analysis:}

Most of the obtained data were statistically expressed as means \pm standard deviation (mean $\pm \mathrm{SD}$ ), and compared using the one-way analysis of variance (ANOVA) followed by Tukey's post hoc test (McHugh, 2011). As regarding sex hormones, non-parametric data were statistically expressed as mean rank using Kruskal-Wallis test for comparison between the different experimental groups followed by Mann-Whitney $U$ test to evaluate the significance of the difference between two groups (Mohammed et al., 2018). A level of probability (P-value) less than 0.05 was considered statistically significant. Statistical analysis was performed using the Statistical Package for the Social Sciences Software, Version 20 for Windows (SPSS Inc., Chicago, Illinois, USA).

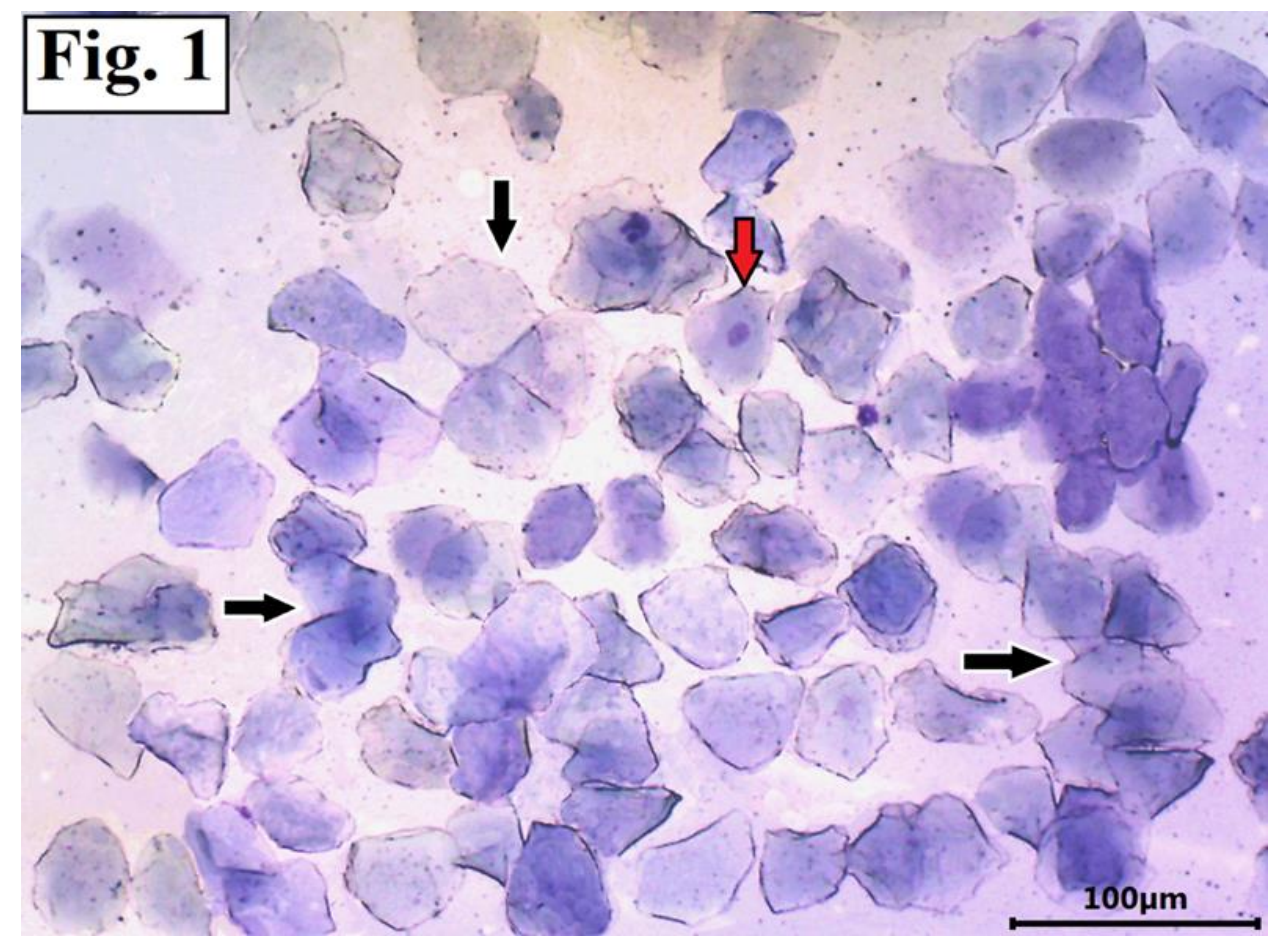

Figure (1): A photomicrograph of stained vaginal smear from the female rate at the estrous phase, showing predominance of large cornified cells arranged in clumps (black arrows). Few cells possess nuclei (red arrows) (Toluidine blue stain; $\mathbf{x} 200$, Scale bar $=100 \mu \mathrm{m}$ ). 


\section{${ }^{3058}$ MONA M. ABD EL-GALIL AND SHYMAA FATHY MOHAMED}

\section{RESULTS}

There was a statistically insignificant change among the two control subgroups ( $p>0.05)$. Therefore, all comparisons were referred to the control group with neglecting its subgrouping.

Effect on the body weight and ovarian weight:

The mean values of initial body weight among rats of all experimental groups were nearly similar with no significant difference $(\mathrm{P}>0.05)$. At the end of the experiment, letrozole-induced PCO (GII) and the recovery (GIV) groups showed nearly similar mean values $(\mathrm{P}>0.05)$ in the final body weight and ovarian weight with a significant increase in these parameters as compared to the control rats $(\mathrm{P}<0.001)$. Fortunately, the final body and ovarian weights remained nearly as the control in the combined flaxseed and letrozole group (GIII), and they were significantly lower than those in GII. Also, flaxseed treated group (GV) recorded a statistically significant decrease in these parameters when compared to the recovery group $(\mathrm{P}<$ 0.001 ), but their values didn't return to normal and revealed significant difference when compared to the control group $(\mathrm{P}<0.05)$ (Table 1).

Table (1): One-way ANOVA followed by post hoc Tukey's comparative statistical analysis of the mean initial, final body weight (BW), and ovarian weight in rats of different groups

\begin{tabular}{|c|c|c|c|c|c|c|}
\hline $\begin{array}{l}\begin{array}{r}\text { Studied } \\
\text { groups }\end{array} \\
\text { Paramete } \\
\text { rs }\end{array}$ & $\begin{array}{c}\text { Control } \\
(\mathbf{n}=6)\end{array}$ & $\begin{array}{c}\text { letrozole- } \\
\text { induced } \\
\text { PCO } \\
(n=6)\end{array}$ & $\begin{array}{c}\text { Flaxseed+ } \\
\text { Letrozole } \\
\quad(\mathbf{n}=6)\end{array}$ & $\begin{array}{c}\text { Recovery } \\
(n=6)\end{array}$ & $\begin{array}{c}\text { Flaxseed } \\
\text { treated } \\
(\mathrm{n}=6)\end{array}$ & $\boldsymbol{P}$ \\
\hline $\begin{array}{c}\text { Initial } \\
\text { BW (g) }\end{array}$ & $185.3 \pm 4.9$ & $185.3 \pm 4.6$ & $188.3 \pm 6.1$ & $186.2 \pm 4.3$ & $184.2 \pm 3.8$ & $>0.05$ \\
\hline $\begin{array}{c}\text { Final BW } \\
\text { (g) }\end{array}$ & $225 \pm 6.5$ & $259.2 \pm 8.6^{\mathrm{a}^{*}}$ & $228.2 \pm 4.9^{\mathrm{b}}$ & $255 \pm 10.5^{a^{*}}$ & $217.5 \pm 5.2^{\mathrm{a}^{*} \mathrm{c}^{*}}$ & $<0.001$ \\
\hline $\begin{array}{c}\text { Ovarian } \\
\text { weight (g) }\end{array}$ & $9.3 \pm 1.03$ & $16.5 \pm 1.4^{\mathrm{a}^{*}}$ & $10.6 \pm 1.04^{b *}$ & $17.1 \pm 1.03^{a^{*}}$ & $11.8 \pm 1.2^{\mathrm{a}^{\mathrm{*} \mathrm{c}^{*}}}$ & $<0.001$ \\
\hline
\end{tabular}

All results were expressed as mean $\pm \mathrm{SD}$; SD: standard deviation; n: number of rats. *P < 0.05 "significant" ${ }^{a}$ significant versus control group

${ }^{\mathrm{b}}$ significant versus letrozole-induced PCO group

${ }^{\mathrm{s}}$ significant versus recovery group

Effect on blood glucose, serum TAC, TNF- $\alpha$, MDA and sex hormones (Estradiol E2, Progesterone, Testosterone, LH, FSH):

Table (2) revealed that the highest recorded mean values of blood glucose were among Letrozole-induced PCO (GII) and the recovery (GIV) groups as compared to the control rats $(\mathrm{P}<0.001)$. Inversely, a significant decrease in the blood glucose level was recorded in both combined flaxseed and letrozole (III) and flaxseed treated (V) groups when compared to Letrozole-induced PCO (GII) and the recovery (GIV) groups respectively $(\mathrm{P}<0.001)$. The value was close to the normal control in GIII $(\mathrm{P}>0.05)$, but remained significantly elevated than control in $\mathrm{GV}(\mathrm{P}<0.05)$.

Letrozole-induced PCO and the recovery groups revealed a significant decrease in the total antioxidant capacity (TAC) coupled with a significant increase in malondialdehyde (MDA) and tumor 
necrotic factor-alpha (TNF- $\alpha)$ when compared to the control rats $(\mathrm{P}<0.001)$. Inversely, flaxseed improved all these markers as demonstrated by a significant increase in TAC, coupled with a significant decrease in TNF- $\alpha$ and MDA in both group III and V when compared to Letrozole-induced PCO and the recovery groups respectively $(\mathrm{P}<0.001)$. However, the improvement in MDA and TNF- $\alpha$ levels in the flaxseed treated group could not reach the control values as there was a significant difference when compared to the control group $(\mathrm{P}<0.05)$ (Table 2$)$.

Regarding serum sex hormonal assay, testosterone and LH levels remarkably increased in Letrozole-induced PCO and the recovery groups, while those of progesterone and estradiol decreased significantly in comparison to the control group $(\mathrm{P}<0.001)$. In combined flaxseed and letrozole (GIII) and flaxseed treated $(\mathrm{GV})$ groups, a significant decrease in the testosterone and LH levels coupled with significantly increased estrogen and progesterone levels recorded in comparison to Letrozole-induced $\mathrm{PCO}$ and the recovery groups respectively $(\mathrm{P}<$ $0.001)$. Fortunately, the values of all these parameters were close to normal in the combined flaxseed and letrozole group ( $\mathrm{P}>0.05$ in comparison to the control group). Also, the level of LH returned to normal in the flaxseed treated group, but testosterone, estradiol and progesterone levels could not reach the control values ( $\mathrm{P}<0.05$ versus control group). As regards FSH levels, insignificant differences were observed between groups $(\mathrm{P}>0.05)$ (Tables 2\& 3).

Table (2): One-way ANOVA followed by post hoc Tukey's comparative statistical analysis of the mean blood glucose, serum antioxidant asseys and sex hormone (Estradiol E2\& Progestrone) levels in the different studied groups

\begin{tabular}{|c|c|c|c|c|c|c|}
\hline $\begin{array}{r}\text { Studied } \\
\text { groups }\end{array}$ & $\begin{array}{l}\text { Control } \\
(n=6)\end{array}$ & $\begin{array}{c}\text { letrozole- } \\
\text { induced } \\
\text { PCO } \\
(n=6)\end{array}$ & $\begin{array}{l}\text { Flaxseed+ } \\
\text { Letrozole } \\
\quad(\mathbf{n}=6)\end{array}$ & $\begin{array}{c}\text { Recovery } \\
(n=6)\end{array}$ & $\begin{array}{c}\text { Flaxseed } \\
\text { treated } \\
(n=6)\end{array}$ & $P$ \\
\hline $\begin{array}{l}\text { Blood glucose } \\
\text { level (mg/dl) }\end{array}$ & $87.8 \pm 7.2$ & $241.7 \pm 10.1^{a^{*}}$ & $104.3 \pm 6.3^{b^{*}}$ & $236.7 \pm 8.2^{\mathrm{a}^{*}}$ & $117.5 \pm 5.9 a^{a *} c^{*}$ & $<0.001$ \\
\hline $\begin{array}{c}\text { TAC } \\
(\mathbf{m M} / \mathbf{L})\end{array}$ & $1.21 \pm 0.1$ & $0.52 \pm 0.10^{\mathrm{a}^{*}}$ & $1.1 \pm 0.2^{b^{*}}$ & $0.45 \pm 0.1^{a^{*}}$ & $0.96 \pm 0.1^{c^{*}}$ & $<0.001$ \\
\hline $\begin{array}{l}\text { TNF- } \alpha \\
(\mathrm{pg} / \mathrm{ml})\end{array}$ & $162.2 \pm 6.6$ & $262.2 \pm 8.2^{\mathrm{a}^{*}}$ & $167.1 \pm 6.1^{b *}$ & $266.7 \pm 7.5^{a^{*}}$ & $179.2 \pm 3.2^{\mathrm{a}^{*} \mathrm{c}^{*}}$ & $<0.001$ \\
\hline $\begin{array}{l}\text { MDA } \\
\text { (ng/L) }\end{array}$ & $0.8 \pm 0.1$ & $3.5 \pm 0.4^{\mathrm{a}^{*}}$ & $0.83 \pm 0.2^{b^{*}}$ & $4.01 \pm 0.2^{a^{*}}$ & $1.07 \pm 0.10^{\mathrm{a}^{*} \mathrm{c}^{*}}$ & $<0.001$ \\
\hline $\begin{array}{c}\text { Estradiol E2 } \\
(\mathrm{pg} / \mathrm{mL})\end{array}$ & $30.3 \pm 3.2$ & $20.3 \pm 2.1^{\mathrm{a}^{*}}$ & $29.1 \pm 0.6^{b^{*}}$ & $21.1 \pm 2.2^{a^{*}}$ & $24.5 \pm 0.8^{\mathrm{a}^{*} \mathrm{c}^{*}}$ & $<0.001$ \\
\hline $\begin{array}{c}\text { Progestrone } \\
(\mathrm{ng} / \mathrm{mL})\end{array}$ & $32.6 \pm 2.5$ & $15.2 \pm 0.8^{a^{*}}$ & $31.8 \pm 2.7^{b *}$ & $16.6 \pm 0.9^{a^{*}}$ & $26.4 \pm 3.1^{\mathrm{a}^{*} \mathrm{c}^{*}}$ & $<0.001$ \\
\hline
\end{tabular}

All results were expressed as mean \pm SD; SD: standard deviation; $n$ : number of rats; TAC: Total antioxidant capacity; MDA: malondialdehyde; TNF- $\alpha$ : tumour necrotic factor-alpha; *P < 0.05 "significant"

asignificant versus control group

${ }^{\mathrm{b}}$ significant versus letrozole-induced PCO group

csignificant versus recovery group 


\section{0}

MONA M. ABD EL-GALIL AND SHYMAA FATHY MOHAMED

Table (3): Kruskal- Wallis test followed by Mann-Whitney $U$ test comparative statistical analysis of the mean ranks of testosterone, LH and FSH in the different studied groups

\begin{tabular}{|c|c|c|c|c|c|c|}
\hline $\begin{array}{r}\text { Studied } \\
\text { groups }\end{array}$ & $\begin{array}{c}\text { Control } \\
(n=6)\end{array}$ & $\begin{array}{c}\text { letrozole- } \\
\text { induced PCO } \\
(n=6)\end{array}$ & $\begin{array}{c}\text { Flaxseed+ } \\
\text { Letrozole } \\
\quad(n=6)\end{array}$ & $\begin{array}{c}\text { Recovery } \\
(n=6)\end{array}$ & $\begin{array}{c}\text { Flaxseed } \\
\text { treated } \\
(n=6)\end{array}$ & $P$ \\
\hline $\begin{array}{c}\text { Testosterone } \\
(\mathrm{ng} / \mathrm{mL})\end{array}$ & 3.83 & $23.5{ }^{a^{*}}$ & $4.83^{b^{*}}$ & $25.5^{a^{*}}$ & $6.83^{\mathrm{a}^{*} \mathrm{c}^{*}}$ & $<0.001$ \\
\hline $\begin{array}{c}\mathbf{L H} \\
(\mathrm{mIU} / \mathrm{mL})\end{array}$ & 7.17 & $22.83^{a^{*}}$ & $8.83^{b^{*}}$ & $26.17^{a^{*}}$ & $12.5^{c^{*}}$ & $<0.001$ \\
\hline $\begin{array}{c}\text { FSH } \\
(\mathrm{mIU} / \mathrm{mL})\end{array}$ & 21.17 & 20.5 & 21.75 & 20.17 & 20.92 & $>0.05$ \\
\hline
\end{tabular}

All results were expressed as mean rank; n: number of rats; LH: Luteinizing hormone; FSH: Folliclestimulating hormone; *P $<0.05$ "significant"

${ }^{a}$ significant versus control group

${ }^{\mathrm{b}}$ significant versus letrozole-induced PCO group

${ }^{\mathrm{c}}$ significant versus recovery group

\section{Histological results:}

Histological examination of the vaginal smear of all rats at the beginning of the experiment revealed normal 4-5-day estrous cycles comprising proestrus, estrus, metestrus and diestrus. In proestrus, oval nucleated epithelial cells, occasionally with a small number of keratinocytes, were detected (Fig. 2a). In estrus, large, angular and irregularly shaped epithelial keratinocytes, mostly non-nucleated arranged in clumps, among which there was a small number of nuclear epithelial cells (Fig. 2b). In metestrus, leukocytes, irregular epithelial keratinocytes and nucleated epithelial cells were detected (Fig. 2c). In diestrus, there were a large number of leukocytes (Fig. 2d). Rats of the control group were in the estrus phase at the time of sacrification (Fig. 2b).
At the end of the experiment, the vaginal smear of the control (GI), combined flaxseed and letrozole group (GIII) and the flaxseed treated group (GV) showed normal cyclical changes. The blood and tissue samples from these groups were obtained in the estrus phase in which large, angular and irregularly shaped epithelial keratinocytes, and a few nuclear epithelial cells were observed in their vaginal smears (Fig. 3a, 3b). However, a few leukocytes were observed microscopically in the vaginal smear of the flaxseed treated group (GV) (Fig. 3c).

The letrozole-induced PCO (GII) and the recovery groups (IV) experienced prolonged diestrus, with the disappearance of the estrus phase. Numerous leukocytes were detected microscopically in the vaginal smears at the time of sacrification (Fig. 3d). 


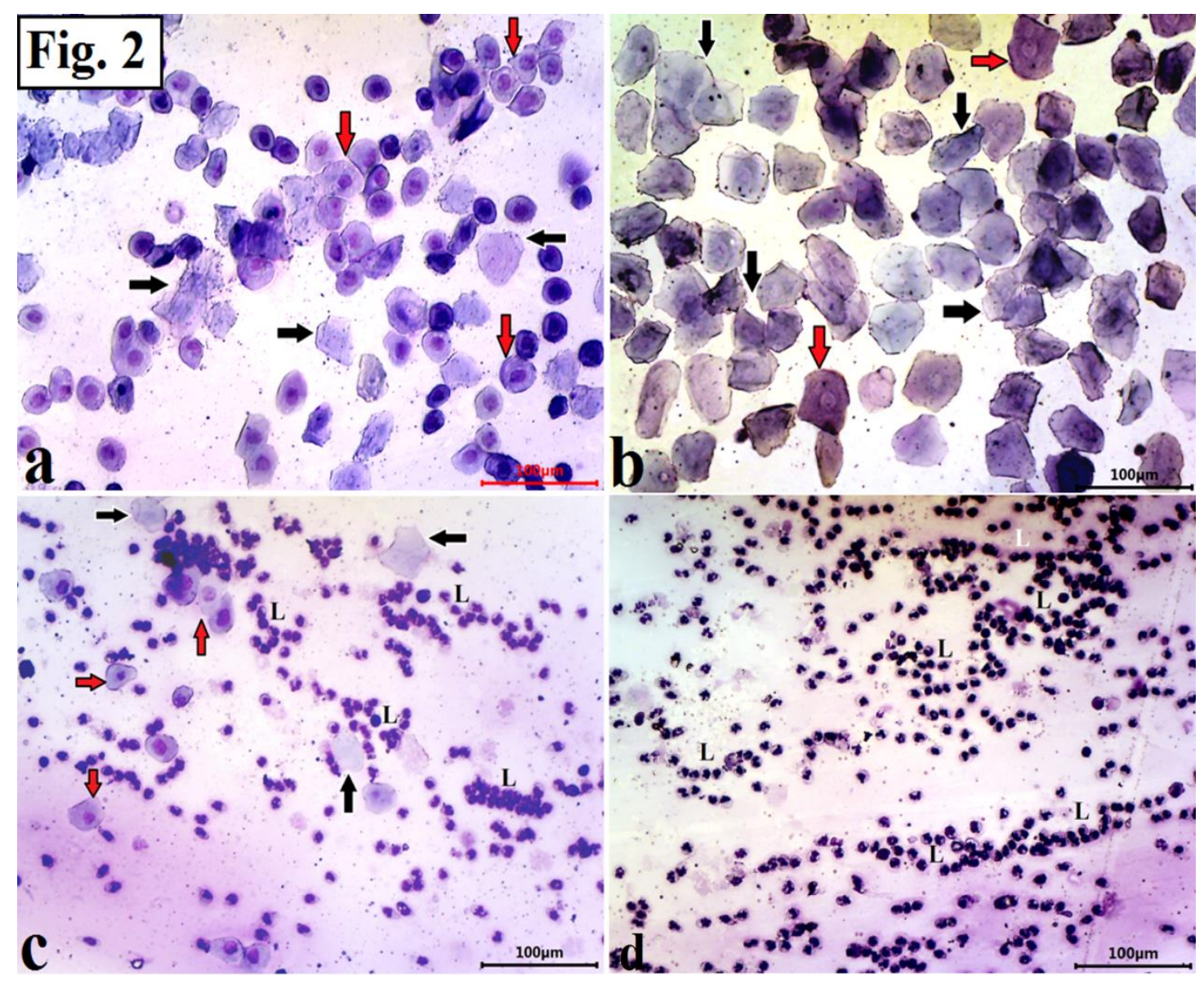

Figure (2): Photomicrographs of stained vaginal smear from the control group: (a) oval nucleated epithelial cells (red arrows), few keratinocytes (black arrows) in the proestrus phase. (b) Large cornified cells arranged in clumps (black arrows) in the estrus phase. Few cells possessing ghost nuclei (red arrows) were noticed. (c) Leukocytes (L), irregular epithelial keratinocytes (black arrows) and nucleated epithelial cells (red arrows) were detected in the metestrus phase. (d) Numerous leukocytes (L) were observed in the diestrus phase (Toluidine blue stain; $x$ 200, Scale bar $=100 \mu \mathrm{m}$ ). 


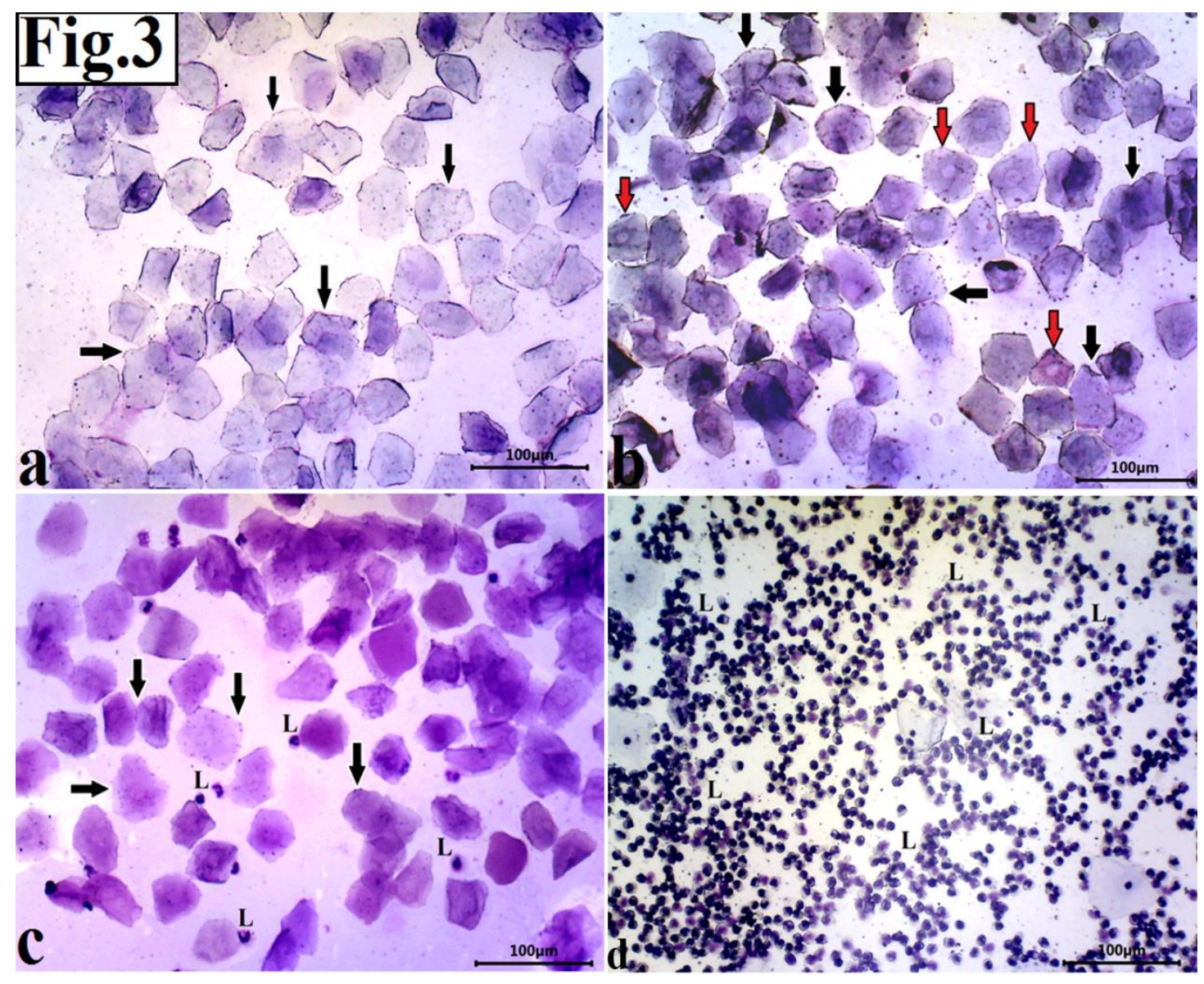

Figure (3): Photomicrographs of stained vaginal smear from the experimental groups: (a, b) Rat's vaginal smears from the control group (I) revealed estrus phase rich in large cornified cells arranged in clumps (black arrows). (b) Combined flaxseed and letrozole group (III) revealed estrus phase rich in large cornified cells arranged in clumps (black arrows). Few cells possessing ghost nuclei (red arrows) were noticed. (c) Rat's vaginal smears from the flaxseed treated group (V) revealed an estrus phase rich in large cornified cells arranged in clumps (black arrows) and few nucleated epithelial cells (red arrows). Leukocytes (L) were scattered in between. (d) Numerous leukocytes (L) were observed in the vaginal smears of the letrozole-induced PCO (GII) and the recovery groups (IV) (Toluidine blue stain; $x$ 200, Scale bar $=100 \mu \mathrm{m}$ ).

\section{Hematoxylin and Eosin (H\&E) stain:}

Histological examination of the ovarian sections of the control group revealed normal histoarchitecture of the ovarian parenchyma in the form of an outer cortex, inner medulla and covered with a single layer of cubical surface epithelium overlying tunica albuginea. Beneath the tunica albuginea several stages of normal follicles and corpus luteum in the form of unilaminar, multilaminar primary follicles, preantral and antral follicles as well as corpora lutea were observed giving the ovarian surface a lobulated appearance (Fig. 4a). The unilaminar primary follicle had an intact primary oocyte with a vesicular nucleus and surrounded by a single layer of cuboidal follicular cells. The antral follicle had a large oocyte surrounded by zona 
pelluicda, cumulus oophorus, corona radiata separated the oocyte from a large liquor-filled antrum. Theca folliculi differentiated into inner vascular theca interna and outer fibrous theca externa (Figs. 4b-4d). Corpus luteum had large granulosa lutein cells with acidophilic cytoplasm and centrally located vesicular rounded nuclei with blood capillaries in between, and surrounded by small theca lutein cells (Fig. 4e). Moreover, the medulla revealed richly vascularized connective tissue and interstitial cells (Fig. 4f).

The combined flaxseed and letrozole group (III) exhibited a high similarity in the normal histological structure of the ovarian tissue compared to the control (Figs. 5a-5f).

Inversely, $\mathrm{H} \& \mathrm{E}$ stained sections of the letrozole-induced PCO (GII) and the recovery groups (IV) revealed severe histopathological alterations in the ovarian tissue in the form of numerous subcapsular cysts of variable shape, size as well as degenerated atretic follicles without oocyte (Figs. 6a, 7a). Thin-walled cystic follicles were characterized by an absent or degenerated oocyte, dehiscent granulosa cells with vacuolated cytoplasm, and shrunk deeply stained pyknotic nuclei detached in the antral cavities surrounded by a thick layer of hyperplastic theca cells (Figs. 6b-6d, 7b7d). Degenerated corpus luteum with vacuolated enlarged granulosa lutein cells was also observed (Figs. 6e, 7e). Moreover, congestion of the interstitial blood capillaries as well as closely packed vacuolated interstitial cells with deeply stained nuclei was frequently detected in the ovarian medulla (Figs. 6f, 7f).

Improvement of the ovarian histoarchitecture was noticed in the flaxseed-treated group (V) where the healthy follicles at different developmental stages almost restored the usual organization (Figs. 8a-8d), despite some vacuolated granulosa lutein cells near the peripheral area of the corpus luteum in comparison to the PCO group (Fig. 8e). The ovarian medulla was closely similar to that of the control group despite congested blood capillaries as well as vacuolated interstitial glandular cells (Fig. 8f). 


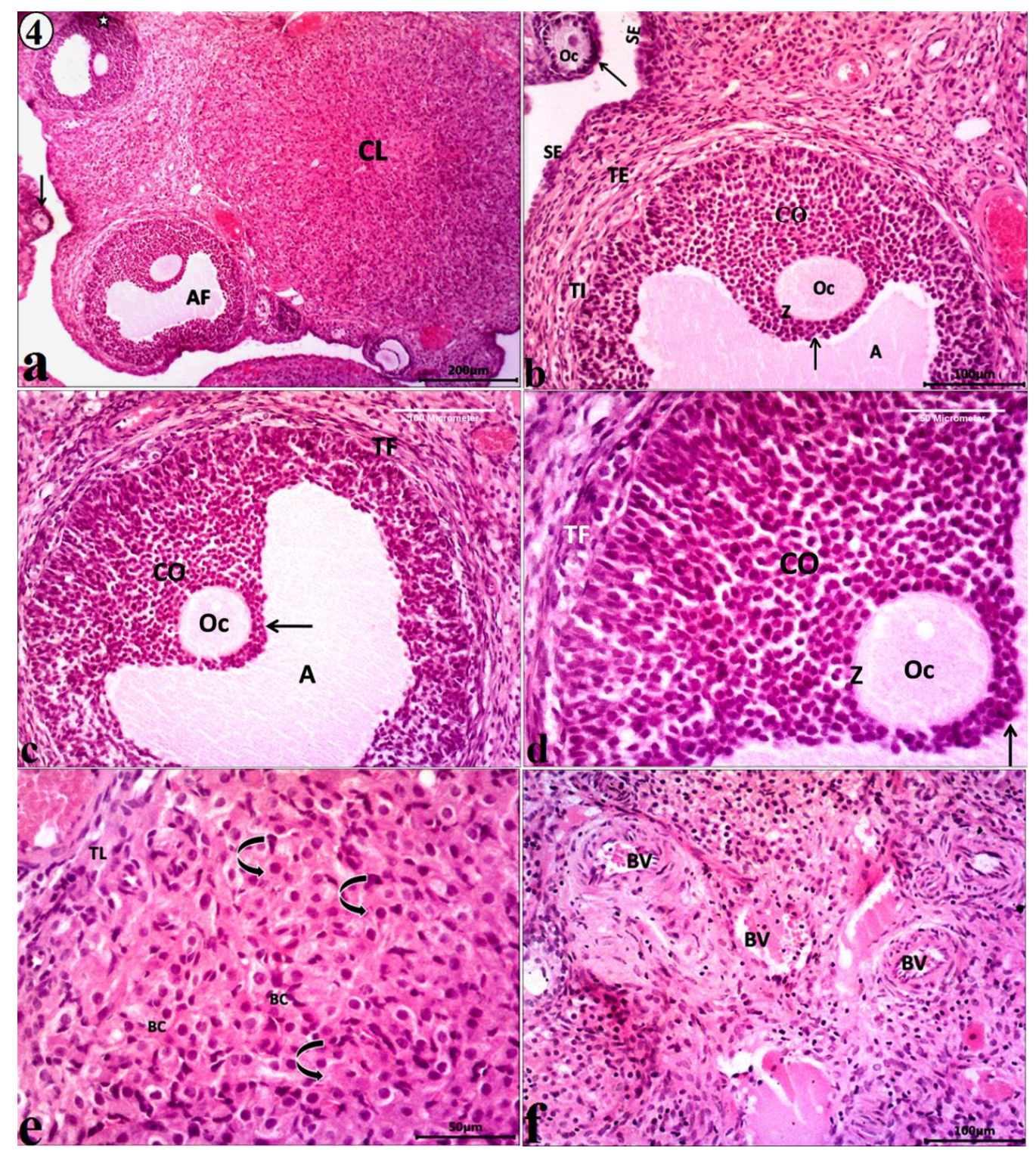

Figure (4): Photomicrographs of the rat ovary from the control group: (a) Unilaminar primary follicle (arrow), preantral (star), antral follicles (AF) as well as corpus luteum (CL) within the ovarian cortex. (b) Cubical surface epithelium (SE), the unilaminar primary follicle (arrow) has oocyte (Oc) with a vesicular nucleus and was surrounded by a single layer of cuboidal follicular cells. (b,c, d) An antral follicle has a large fluid-filled antrum (A), large oocyte (Oc) was surrounded by zona pollucida $(\mathrm{Z})$, corona radiata (arrow) and cumulus oophorus (CO) connected the oocyte to the follicle. The theca folliculi (TF) differentiated into inner theca interna (TI) and outer theca externa (TE). (e) Part of corpus luteium has large polygonal granulosa lutein cells with acidophilic cytoplasm and centrally located round vesicular nuclei (curved arrows), and blood capillaries (BC) in between and surrounded by theca lutein cells (TL). (f) Numerous blood vessels (BV) within loose connective tissue showing fibroblasts and interstitial cells in the ovarian medulla $(H \& E$ a $\times 100$, Scale bar $=200 \mu \mathrm{m}$; b,c and f $\times 200$, Scale bar $=100 \mu \mathrm{m}$; d and e $x 400$, Scale bar $=50 \mu \mathrm{m})$. 


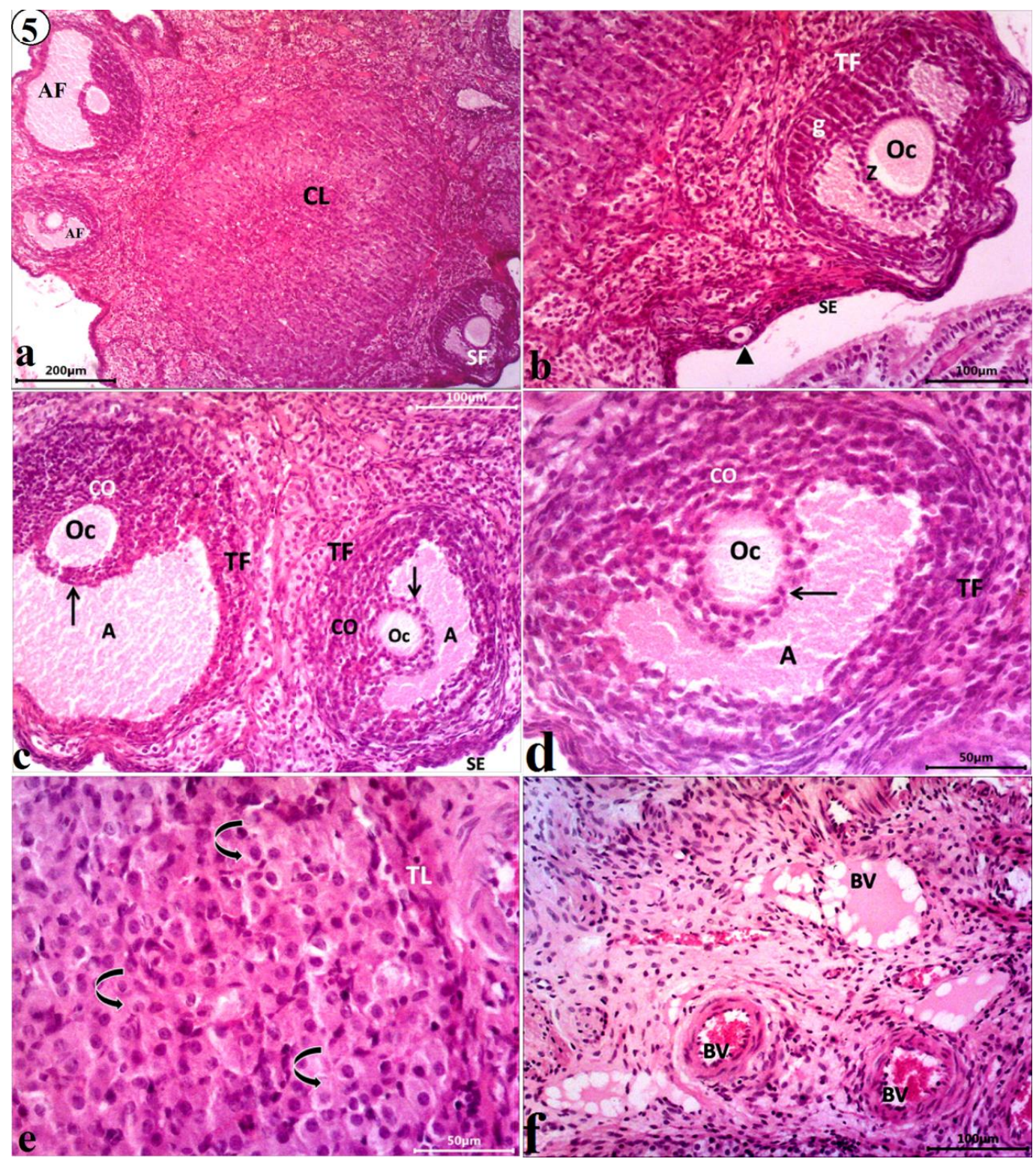

Figure (5): Photomicrographs of the rat ovary from the combined flaxseed and letrozole group: (a) Secondary follicle (SF), antral follicles (AF) as well as corpus luteum (CL) within the ovarian cortex. (b) Cubical surface epithelium (SE), the primordial follicle (arrowhead) has an oocyte surrounded by a single layer of flattened granulosa cells. Secondary follicle with multiple fluid-filled cavities, oocyte (Oc) appeared surrounded by zona pollucida (Z), granulosa cells (g), and theca folliculi (TF). (c, d) Antral follicles with large fluid-filled antrum (A), oocytes (Oc), zona pollucida (Z), corona radiata (arrows), cumulus oophorus (CO) and surrounded by theca folliculi (TF). (e) Corpus luteium has large polygonal granulosa lutein cells with eosinophilic cytoplasm and centrally located round nuclei (curved arrows) with blood capillaries (BC) in between and surrounded by theca lutein cells (TL). (f) The medulla contained numerous blood vessels (BV) within loose connective tissue showing fibroblasts and interstitial cells (H\&E a x 100, Scale bar= $200 \mu \mathrm{m} ; b, c$ and $\mathrm{f} \times 200$, Scale $b a r=100 \mu \mathrm{m} ; \mathrm{d}$ and e $x 400$, Scale bar $=50 \mu \mathrm{m})$. 


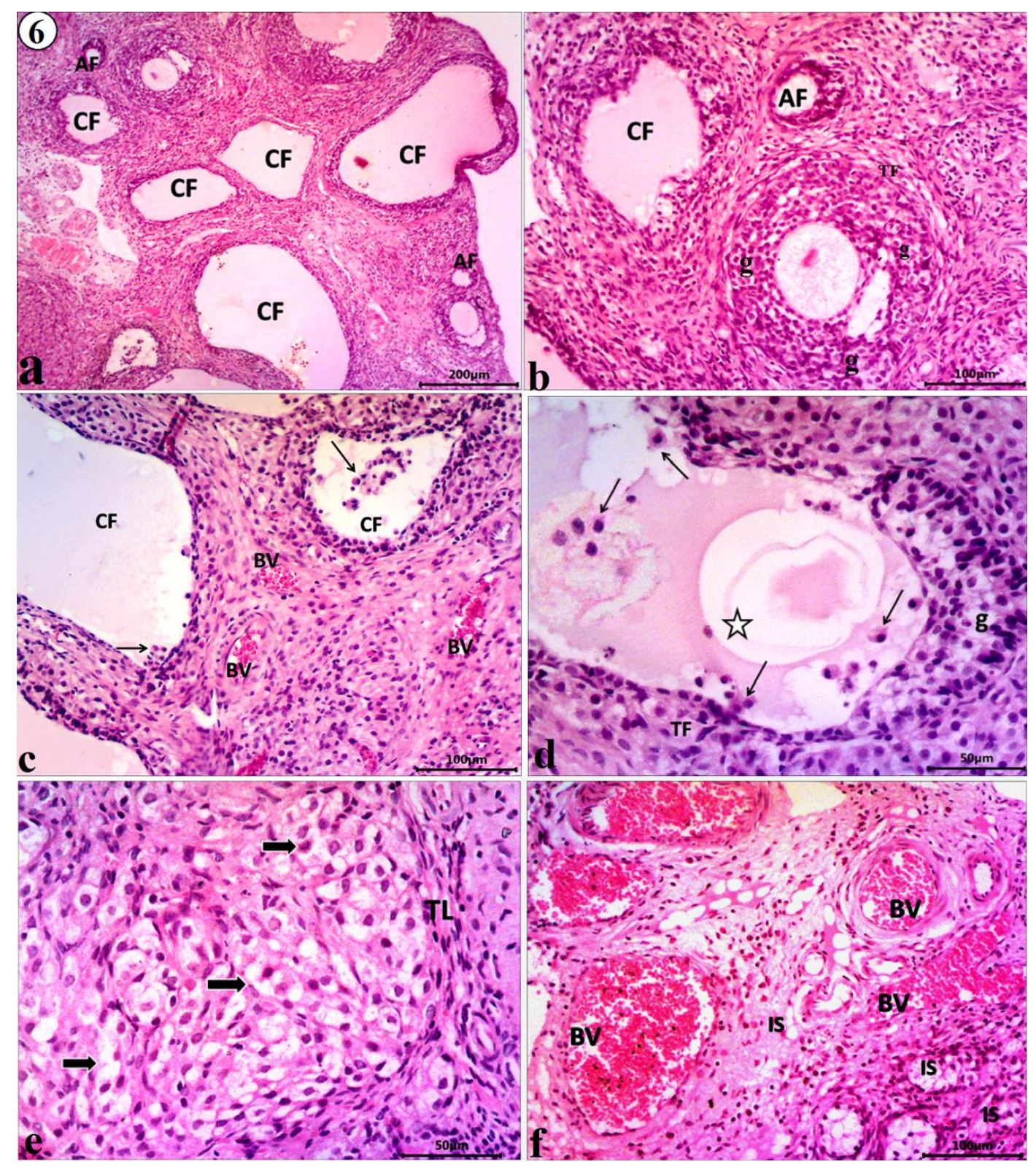

Figure (6): Photomicrographs of the rat ovary from the letrozole-induced PCO group: (a) Numerous subcapsular follicular cysts $(\mathrm{CF})$ with the disappearance of oocytes and amorphous acidophilic materials in their lumens. Degenerated atretic follicles (AF) were also evident. (b) Atretic follicle (AF), cystic follicles (CF), degenerated follicle has vacuolated granulosa cells ( $\mathrm{g}$ ) and was surrounded by theca cells (TF). (c, d) Thin-walled cystic follicles showed degenerated oocyte (star), detached apoptotic granulosa cells with deeply stained pyknotic nuclei into the antral cavity (arrows). Few degenerated vacuolated granulosa cells (g) surrounded by theca folliculi cells (TF). (e) Numerous vacuolated granulosa lutein cells with deeply stained nuclei (arrows) surrounded by theca lutein (TL). (f) Dilated congested blood vessels (BV) and vacuolated interstitial cells (IS) within the ovarian medulla $(H \& E$ a $\times 100$, Scale bar $=200 \mu \mathrm{m} ; b, c$ and $\mathbf{f} \times 200$, Scale bar $=100 \mu \mathrm{m}$ ;d and e $x 400$, Scale bar $=50 \mu \mathrm{m})$. 


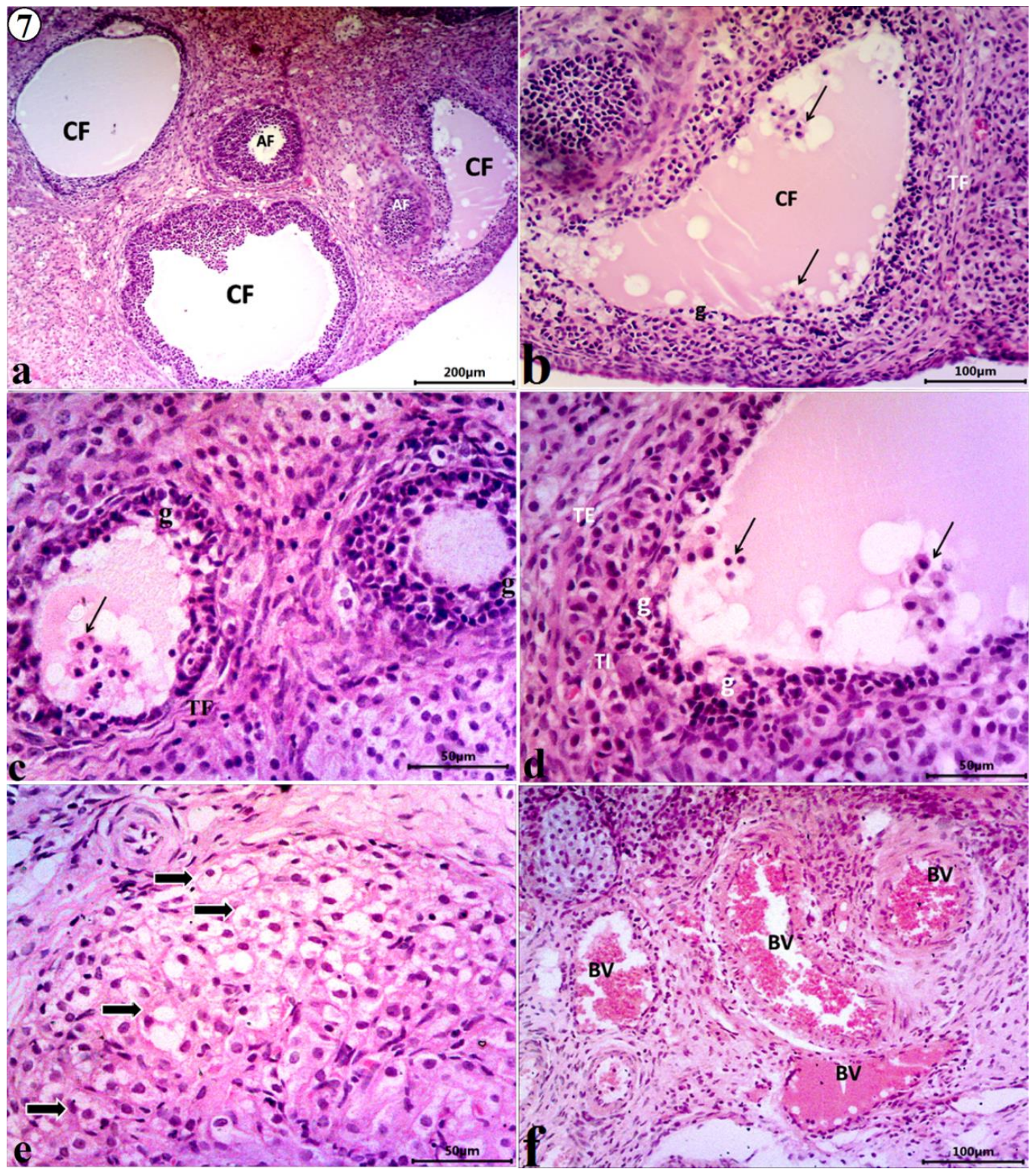

Figure (7): Photomicrographs of the rat ovary from the recovery group: (a) Degenerated atretic follicles (AF), subcapsular follicular cysts (CF) with the disappearance of oocytes and amorphous acidophilic materials in their lumens. (b,c, d) Thin-walled cystic follicle (CF) showed detached apoptotic granulosa cells into the antral cavity with deeply stained pyknotic nuclei (arrows) and few degenerated vacuolated granulosa cells (g) surrounded by a thick theca folliculi (TF) that differentiated into vacuolated theca interna (TI) and theca externa (TE). (e) Vacuolated granulosa lutein cells have deeply stained nuclei (arrows). (f) Dilated congested blood vessels (BV) within the ovarian medulla (H\&E a $x$ 100, Scale bar $=200 \mu \mathrm{m}$; b,c and f x200, Scale bar $=100 \mu \mathrm{m}$;d and e $x 400$, Scale bar $=50 \mu \mathrm{m}$ ). 

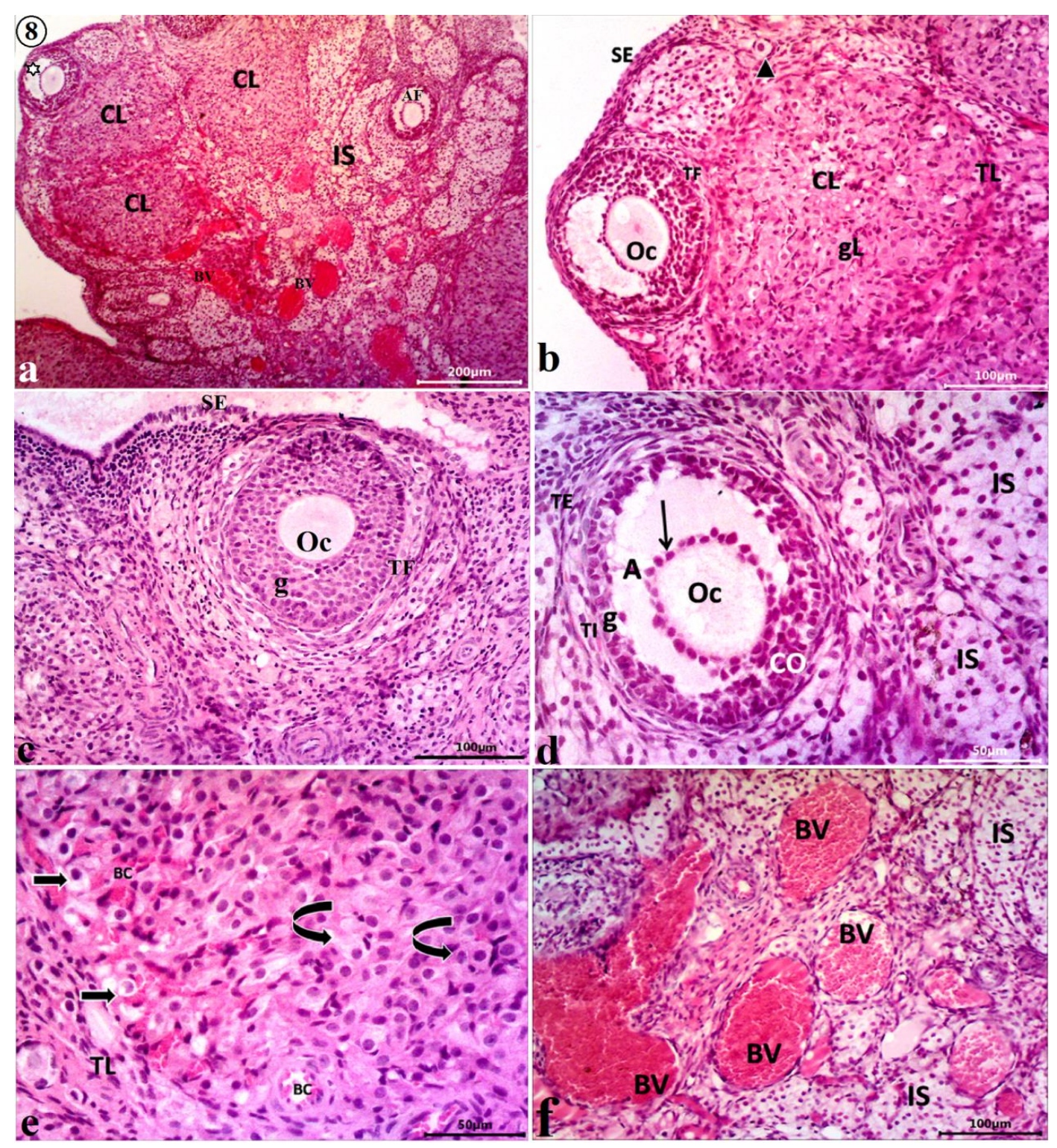

Figure (8): Photomicrographs of the rat ovary from the flaxseed-treated group: (a- d) More or less apparent restoration of the normal histological structure. (a) Preantral (star), antral follicles (AF) ,corpora lutea (CL), interstitial cells (IS) within the ovarian cortex, and congested blood vessels within the ovarian medulla. (b, c) cubical surface epithelium (SE), primordial follicle (arrowhead), corpora lutea (CL) had granulosa lutein cells (gL) and surrounded by theca lutein cells (TL). (c) The multilaminar primary follicle had oocyte (Oc), granulosa cells (g) and surrounded by theca folliculi (TF). (d) Fluid-filled antrum (A), oocytes (Oc), corona radiata (arrows), cumulus oophorus (CO), inner theca interna (TI) and outer theca externa (TE) cells and vacuolated cells of interstitial tissue (IS). (e) Normal granulosa lutein cells (curved arrows) with few vacuolated granulosa lutein cells (arrows) near the peripheral area of the corpus luteum, and surrounded by theca lutein cells (TL). (f) Dilated congested blood vessels (BV) and vacuolated interstitial cells (IS) within the ovarian medulla $(H \& E$ a $\times 100$, Scale bar $=200 \mu \mathrm{m}$; b,c and $\mathbf{f} \times 200$, Scale bar $=$ $100 \mu \mathrm{m} ; \mathrm{d}$ and e $\mathrm{x400}$, Scale bar $=50 \mu \mathrm{m})$. 


\section{Masson's trichrome stain:}

Masson's trichrome stained sections of the control (GI) and the combined flaxseed + letrozole group (GIII) were closely similar. They revealed thin delicate green collagen fibers in the tunica albuginea as well as delicate cortical connective tissue septa (Figs. 9a-9c, 10a10c). Perivascular fine collagenous fibers of normal density and distribution, and admixed with the ground substance within the ovarian medulla were also observed (Figs. 9d, 10d).

Letrozole-induced PCO (GII) and the recovery (GIV) groups revealed recruited fine collagen fibers in the ovarian cortex around the cystic follicles (Figs. 11a-11c, 12a-12c) with an increase in the density and distribution of the collagen fibers in the ovarian medulla around the congested blood vessels (Figs. 11d, 12d).

On the contrary, there was a nearly normal dispersion of fine collagen fibers in the flaxseed-treated group (V) that appeared more or less similar to that of the control, despite that denser collagen fibers appeared around the congested blood vessels in the ovarian medulla compared to the control group (Fig. 13).

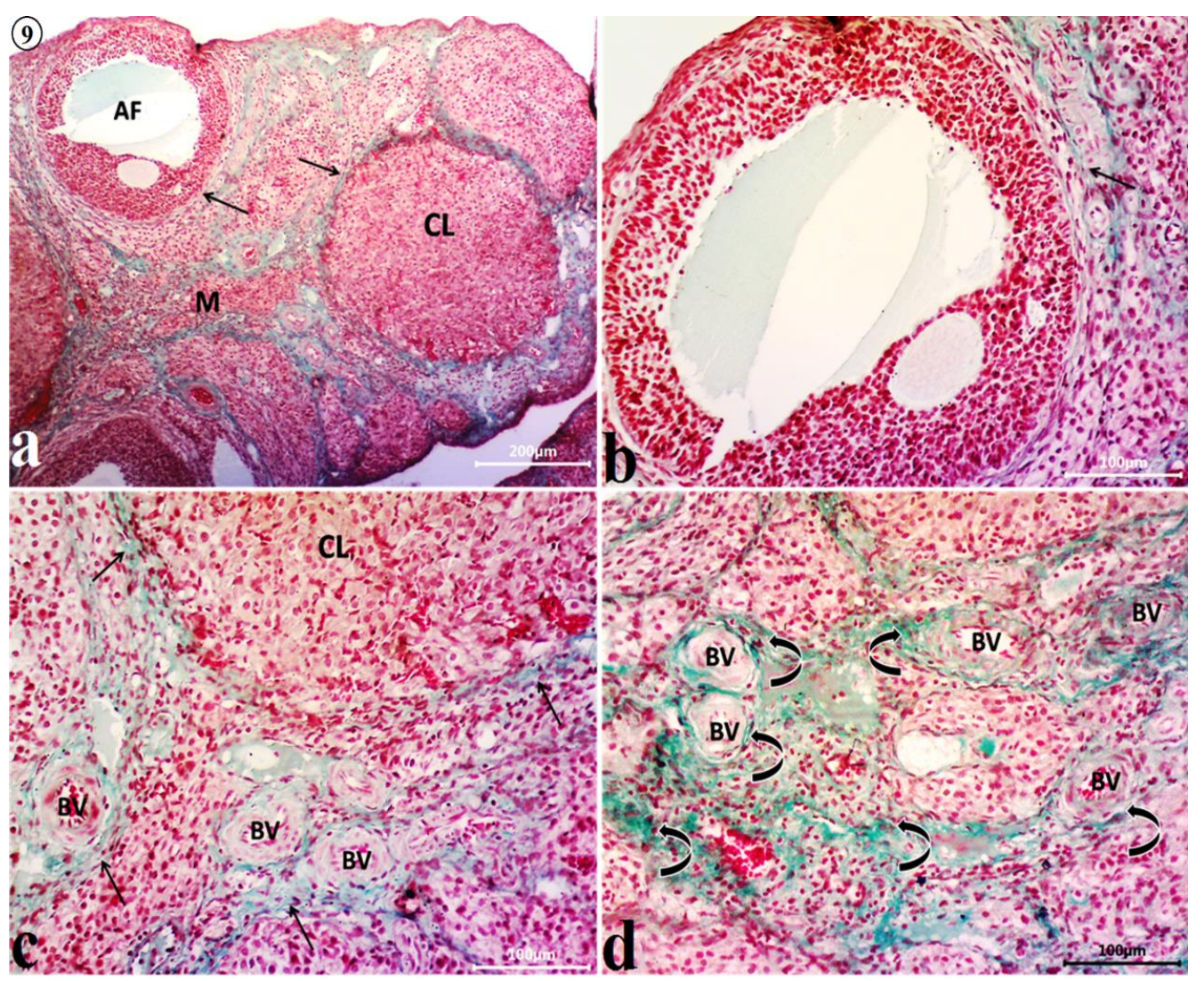

Figure (9): Photomicrographs of the rat ovary from the control group: (a,b, c) Fine collagenous fibers (arrows) within the theca externa around the antral follicle (AF), corpus luteum (CL) and around blood vessels (BV) of the ovarian cortex. (d) Delicate collagenous fibers admixed with ground substance (curved arrows) and around blood vessels (BV) in the ovarian medulla (Masson's trichrome stain a x100, Scale bar; $200 \mu \mathrm{m} ; \mathbf{b , c}$ and $d$ x200, Scale bar; $100 \mu \mathrm{m})$. 


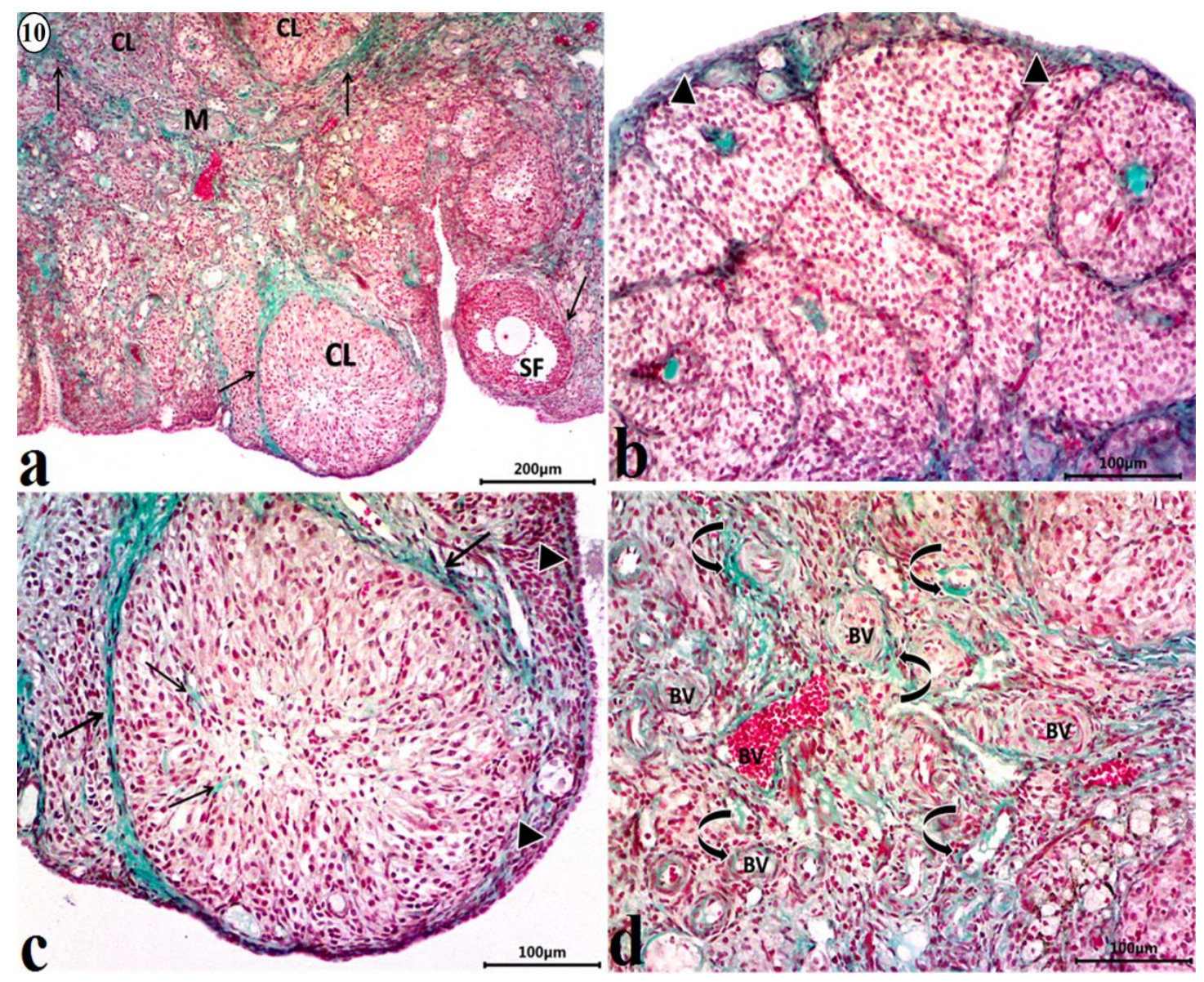

Figure (10): Photomicrographs of the rat ovary from the combined flaxseed and letrozole group: (a) Fine collagen fibers (arrows) around secondary follicle (SF), the corpora lutea (CL) and admixed with the ovarian medulla (M). (b, c) A thin layer of collagenous fibers in tunica albuginea (arrowheads). (c) Delicate collagen fibers (arrows) in the theca lutein externa and in between the granulosa lutein cells of the corpus luteum. (d) Perivascular (BV) fine collagen fibers of normal density and distribution and admixed with ground substance (curved arrows) in the ovarian medulla (Masson's trichrome stain a x100, Scale bar; $200 \mu \mathrm{m} ; \mathrm{b}, \mathrm{c}$ and $\mathrm{d}$ x200, Scale bar; $100 \mu \mathrm{m})$. 


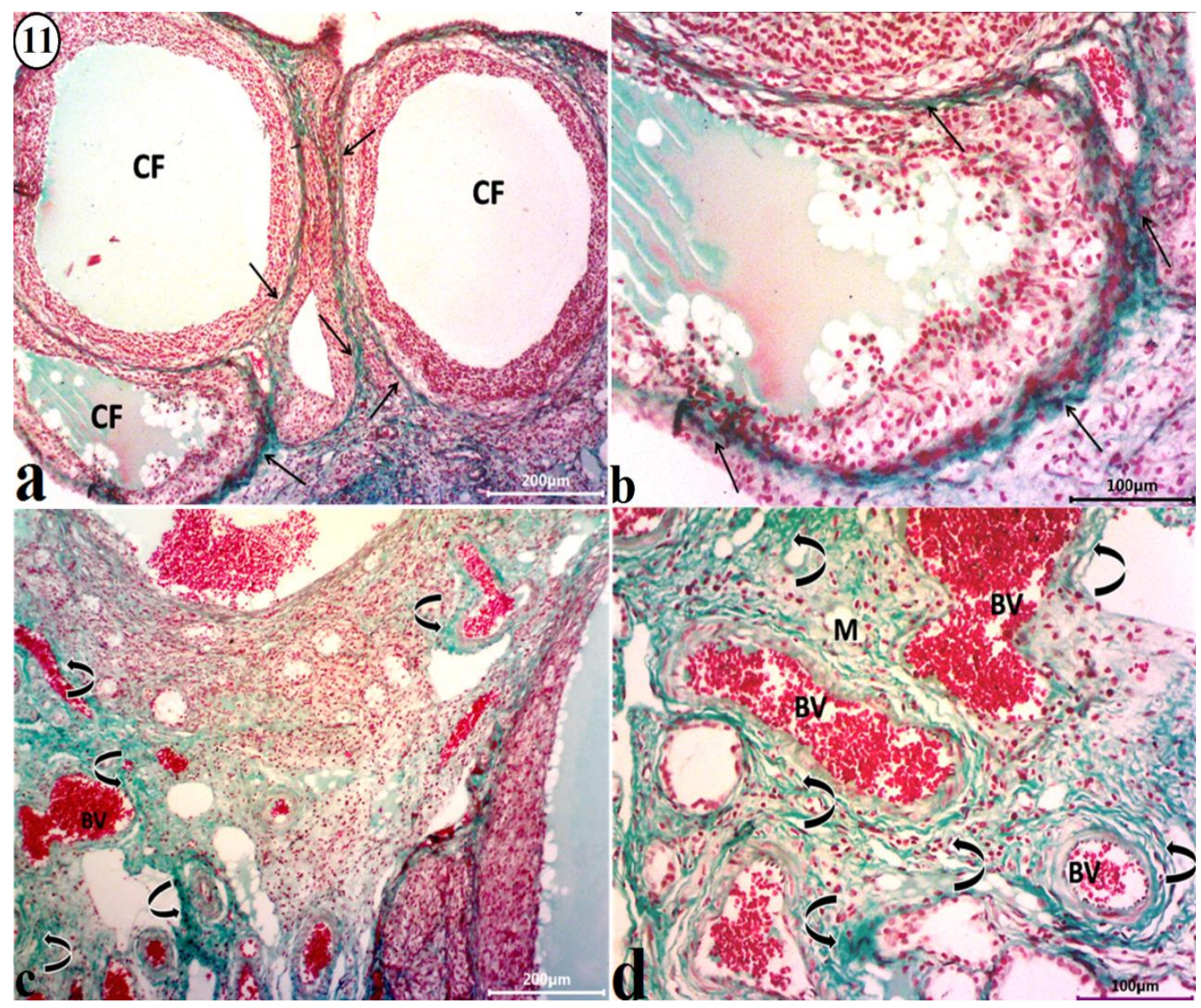

Figure (11): Photomicrographs of the rat ovary from the letrozole-induced PCO group: (a, b) Fine collagen fibers (arrows) around the cystic follicles (CF) within the ovarian cortex. (c, d) Dense collagen fibers (curved arrows) around the congested blood vessels (BV) in the ovarian medulla (Masson's trichrome stain a $x 100$, Scale bar; $200 \mu \mathrm{m} ; \mathrm{b}, \mathrm{c}$ and $d$ x200, Scale bar; $100 \mu \mathrm{m})$. 


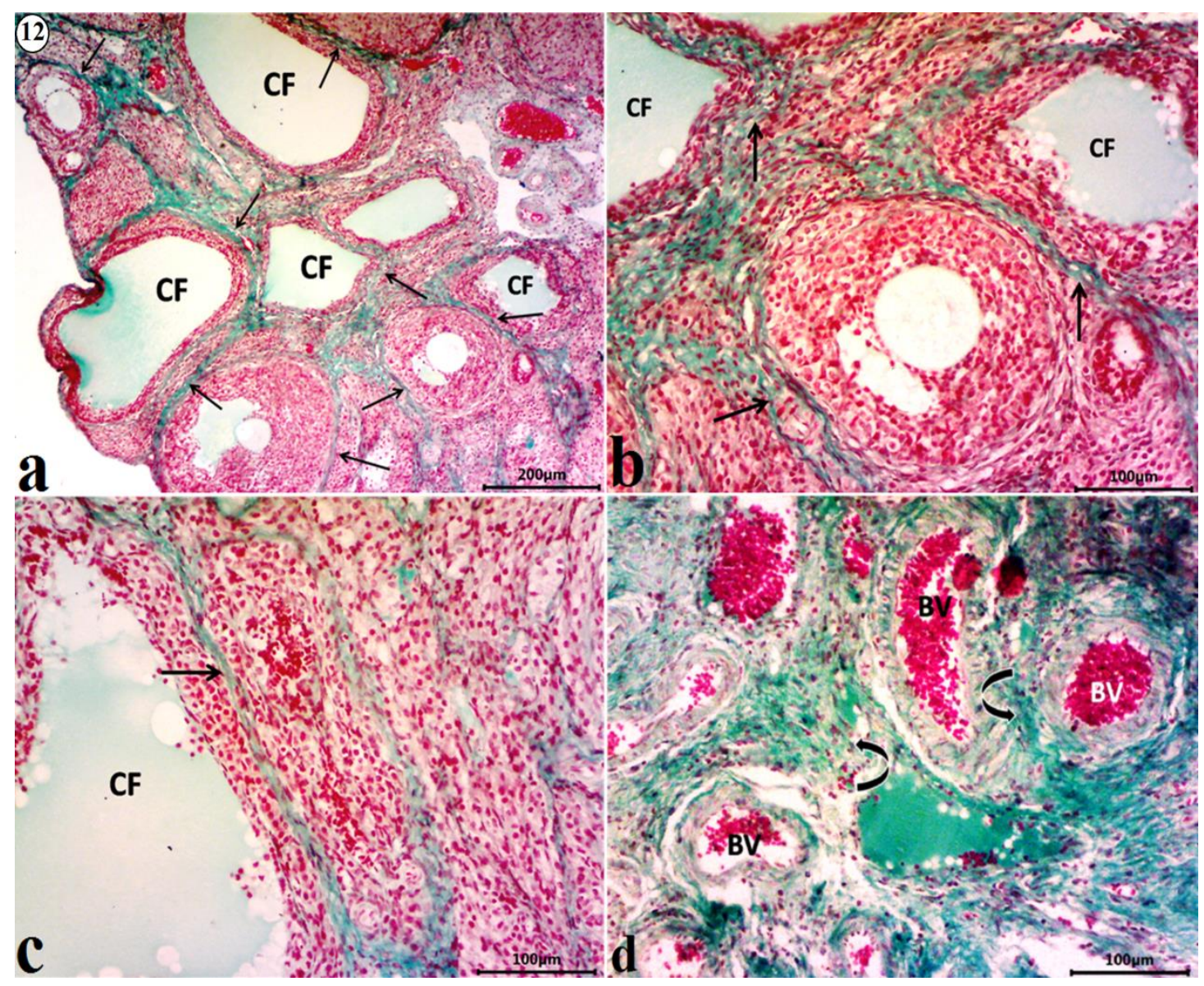

Figure (12): Photomicrographs of the rat ovary from the recovery group: (a,b, c) Fine collagen fibers (arrows) around the cystic follicles (CF) in the ovarian cortex. (d) Increased density and distribution of collagenous fibers (curved arrows) in the ovarian medulla and around the congested blood vessels (BV) (Masson's trichrome stain a x100, Scale bar; $200 \mu \mathrm{m} ; \mathrm{b}, \mathrm{c}$ and d x200, Scale bar; $100 \mu \mathrm{m})$. 


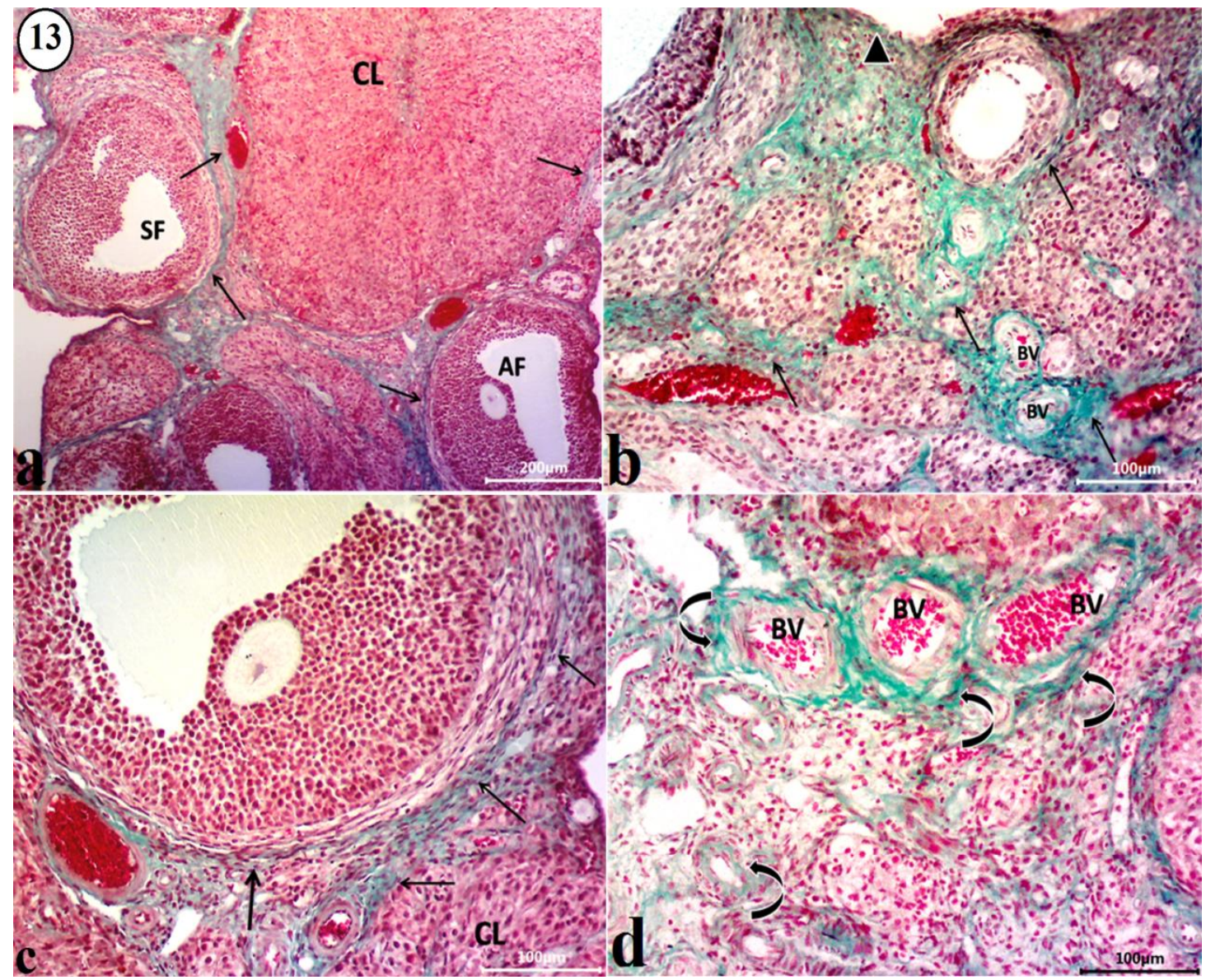

Figure (13): Photomicrographs of the rat ovary from the flaxseed-treated group: (a,b, c) Normal density and distribution of delicate collagen fibers in the tunica albuginea (arrowheads), around secondary follicle (SF), the antral follicle (AF) and the corpus luteum (CL). (d) Delicate collagenous fibers around the blood vessels within the ovarian medulla more or less as control (Masson's trichrome stain a x100, Scale bar; $200 \mu \mathrm{m}$; b,c and d x200, Scale bar; $100 \mu \mathrm{m})$.

\section{Electron microscopic results:}

In the control group (GI), mature Graafian follicle appeared with many layers of large polyhedral granulosa cells connected by intact junctions, and surrounded by relatively flattened theca interna cells with flattened nuclei. The cytoplasm of granulosa cells depicted euchromatic nuclei of different sizes and shapes (Figs. 14a, 14b), oval to round mitochondria with tubular cristae, and few flattened cisternae of the rough endoplasmic reticulum (Fig. 14b). The oocyte appeared surrounded by wide electron semitranslucent zona pellucida separated it from the granulosa cells. Both the oolema and plasma membrane of the granulosa cells have microvilli project into the zona pellucida (Fig. 14c).

The corpus luteum had large polyhedral granulosa lutein cells with euchromatic nuclei had shallow indentations (Figs. 14d, 14e), few variable-sized electron lucent lipid droplets, mitochondria with tubular cristae and lysosomes (Figs. 14e, 14f). A basement membrane as well as a thin layer of collagen fibers cut in different 


\section{MONA M. ABD EL-GALIL AND SHYMAA FATHY MOHAMED}

directions separated the granulosa lutein cells from the surrounding theca lutein cells. Theca lutein interna had flattened euchromatic nuclei, few lipid droplets, scattered mitochondria, and a few rough endoplasmic reticulums (Figs. 14g, 14h).

In the combined flaxseed and letrozole group (GIII), the secondary follicle exhibited many layers of polyhedral granulosa cells separated by liquor-filled spaces and surrounded by theca folliculi. The cytoplasm of granulosa cells contained euchromatic nuclei, oval to elongated mitochondria, scattered rough endoplasmic reticulum, lysosomes and separated from the surrounding theca lutein cells by a basement membrane as well as a thin layer of collagen fibers cut in different directions (Figs. 15a-15d). Polygonal theca interna cells had euchromatic nuclei, few lipid droplets and scattered rough endoplasmic reticulum (Figs. 15b-15d). The corpus luteum appeared closely similar to that of the control group (Figs. 15a-15h).

On the other hand, electron microscopic examination of ovarian sections of the letrozole-induced PCO (GII) and the recovery group (GIV) revealed a follicular cyst contained amorphous substances, degenerated granulosa cells spilled in the antrum. The cytoplasm exhibited numerous electronlucent and electron-dense lipid droplets, swollen mitochondria with disrupted cristae, empty spaces and abundant variable-sized multivesicular bodies enclosed electron opaque material (Figs. 16a, 16b, 17a-19c). A cystic wall formed of degenerated theca interna contained many lipid droplets (Figs. 16c, 17d). Moreover, expanded intercellular spaces between theca externa cells with collagen fibers cut in different directions were also observed (Fig. 16d).

The obvious degenerated corpus luteum had deformed nuclei with margination of condensed chromatin and dilated perinuclear cisternae. Numerous variable-sized electron lucent lipid droplets, areas of rarified cytoplasm, lysosomes, dilated Golgi apparatus and abnormal swollen mitochondria with disrupted cristae were also detected. Cells of theca lutein interna contained variablesized electron lucent lipid droplets (Figs. 16e-16h, 17e-17h).

Nearly, normal features of the ovarian sections were depicted in the flaxseedtreated group $(\mathrm{GV})$. The secondary follicle contained liquor folliculi between normal granulosa cells and surrounded by theca interna and theca externa layers. Interstitial stromal cells appeared with no lipid droplets in their cytoplasm (Figs.18a$18 \mathrm{c})$. Corpus luteum was more or less as in the control group (Figs. 18d-18f). 


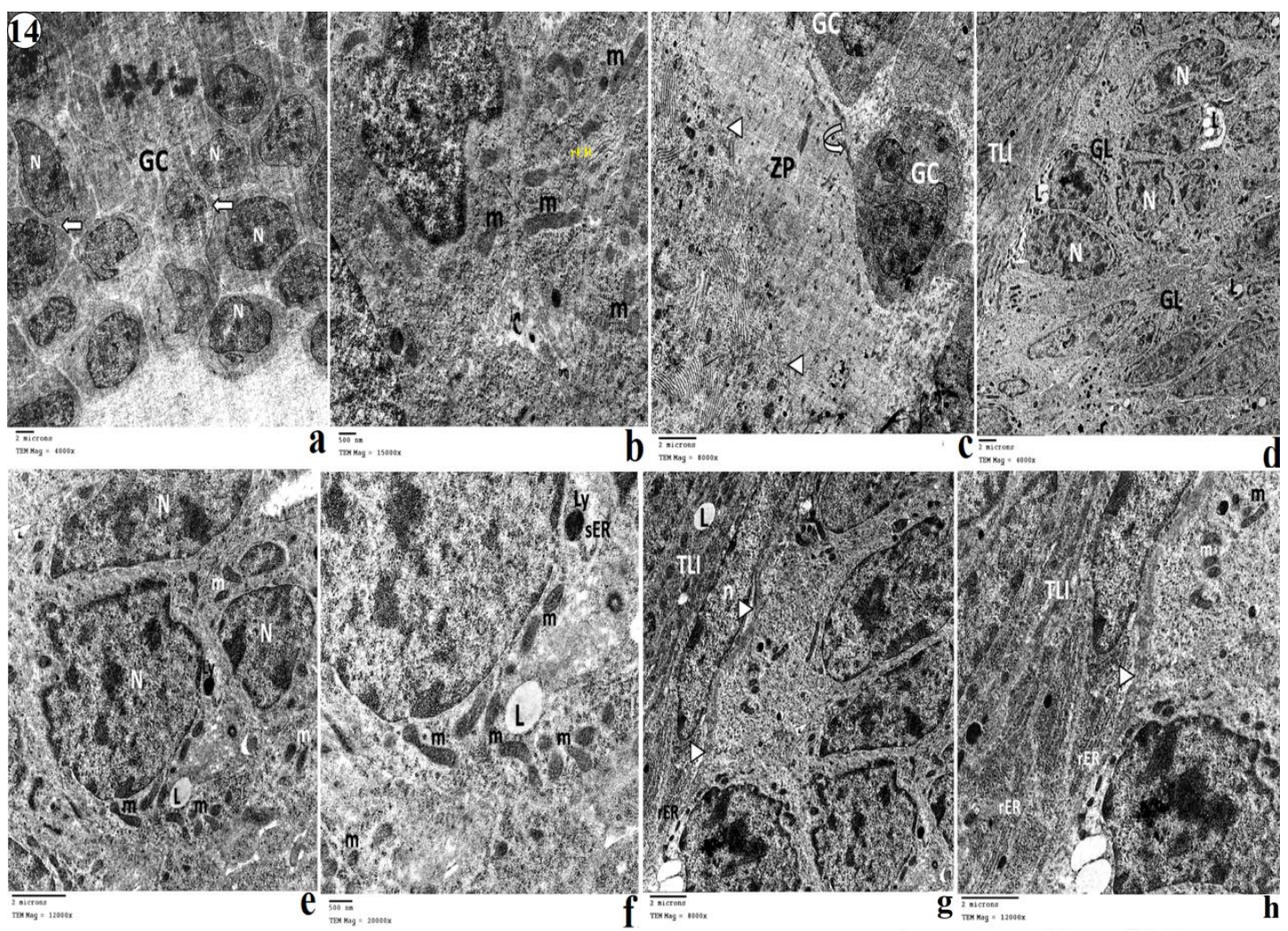

Figure (14): Electron photomicrographs from the ovary of the control group: (a) Polyhedral granulosa cells (GC) of the Graffian follicle with intact junctions (arrows) inbetween. They had euchromatic nuclei $(\mathrm{N})$ of different sizes and shapes. (b) Oval to rounded normal mitochondria $(\mathrm{m})$ with tubular cristae and sparse of the rough endoplasmic reticulum (rER) in the cytoplasm of granulosa cells. (c) Oolema (arrowheads) and plasma membrane (curved arrows) of the granulosa cells (GC) showed microvilli projected into the electron semitranslucent zona pellucida (ZP). (d, e) Polyhedral granulosa lutein cells (GL) of corpus luteum with indented euchromatic nuclei (N), lipid droplets (L) and surrounded by polyhedral theca lutein interna (TLI). (e, f) The cytoplasm of granulosa lutein cell contained mitochondria $(\mathrm{m})$ with tubular cristae, lysosomes (Ly), and electron lucent lipid droplets (L). (g, h) Theca lutein interna cells (TLI) had flattened euchromatic nuclei (n), few lipid droplets (L), sparse of rough endoplasmic reticulum (rER). Collagen fibers (arrowheads) cut in different directions separated the granulosa lutein cells from the surrounding theca lutein interna cells (TEM; a, d x4000; bx15000; c, g x8000; e, h $\mathrm{x12000}$ and $\mathrm{f} \times 20000$ ). 

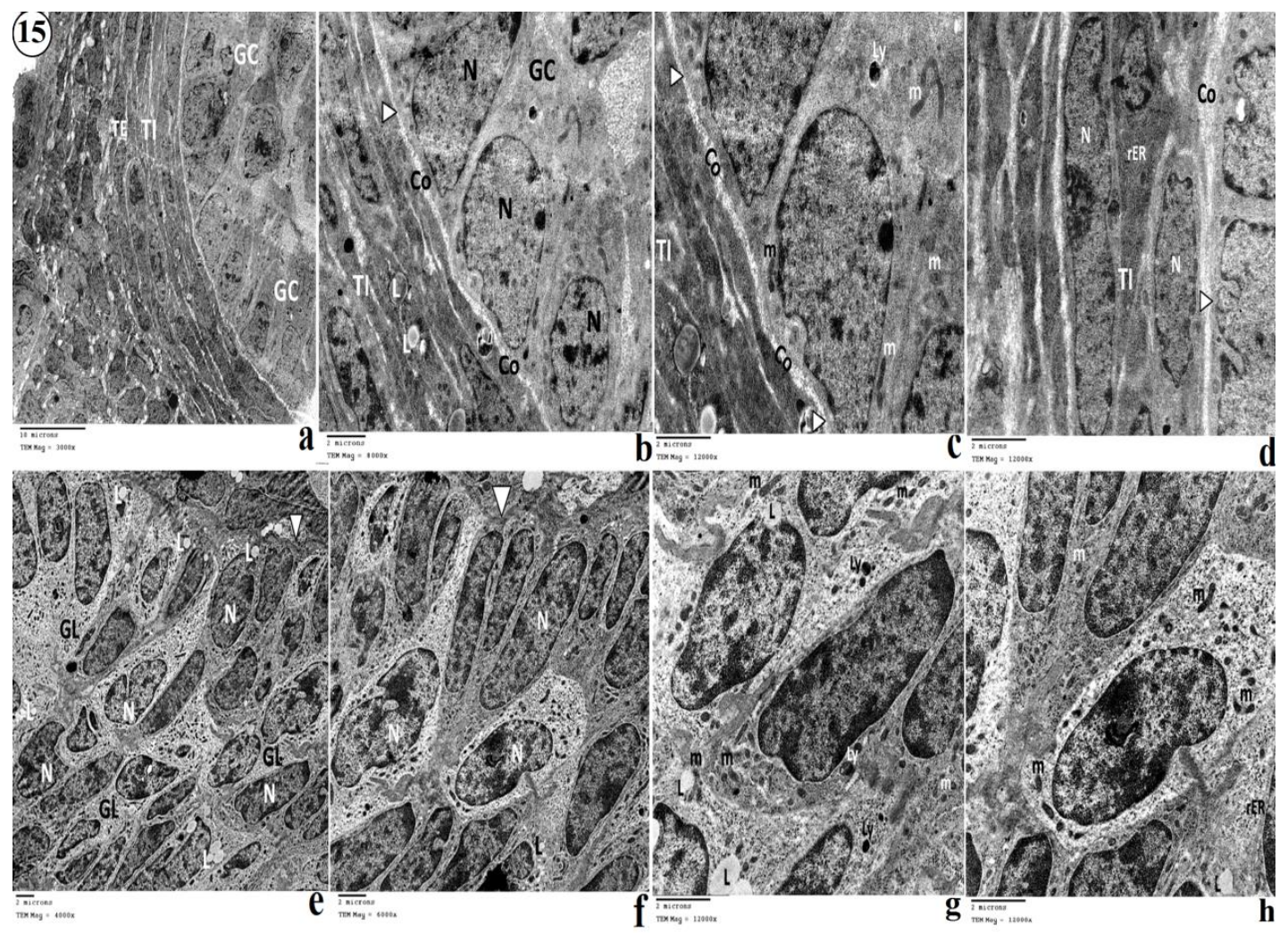

Figure (15): Electron photomicrographs from the combined flaxseed and letrozole group: (a) Secondary ovarian follicle had granulosa cells (GC) and was surrounded by oval theca interna cells (TI) and flattened theca externa cells (TE). (b, c) Polyhedral granulosa cells (GC) had euchromatic nuclei (N) of different sizes and shapes, oval and elongated scattered rounded mitochondria ( $\mathrm{m}$ ) and lysosomes (Ly). (b-d) Basal lamina (arrowhead) as well as a thin layer of collagen fibers $(\mathrm{Co})$ cut in different directions separated granulosa cells from the surrounding theca interna cells (TI), and lipid droplets (L) in the cytoplasm of theca interna cells (TI). (d) Theca interna cells (TI) had euchromatic oval nuclei (N) with prominent nucleoli and rough endoplasmic reticulum (rER). (e-g) Polyhedral granulosa lutein cells (GL) of corpus luteum, euchromatic nuclei $(\mathrm{N})$, few variable-sized electron lucent lipid droplets (L), and basal lamina (arrowhead). (g, h) Mitochondria (m) with tubular cristae, lysosomes (Ly), sparse of the rough endoplasmic reticulum (rER), and few electron-lucent lipid droplets (L) in granulosa lutein cells cytoplasm (TEM a x3000; b x8000; c, d, g, h x12000; e x4000 and f x6000). 


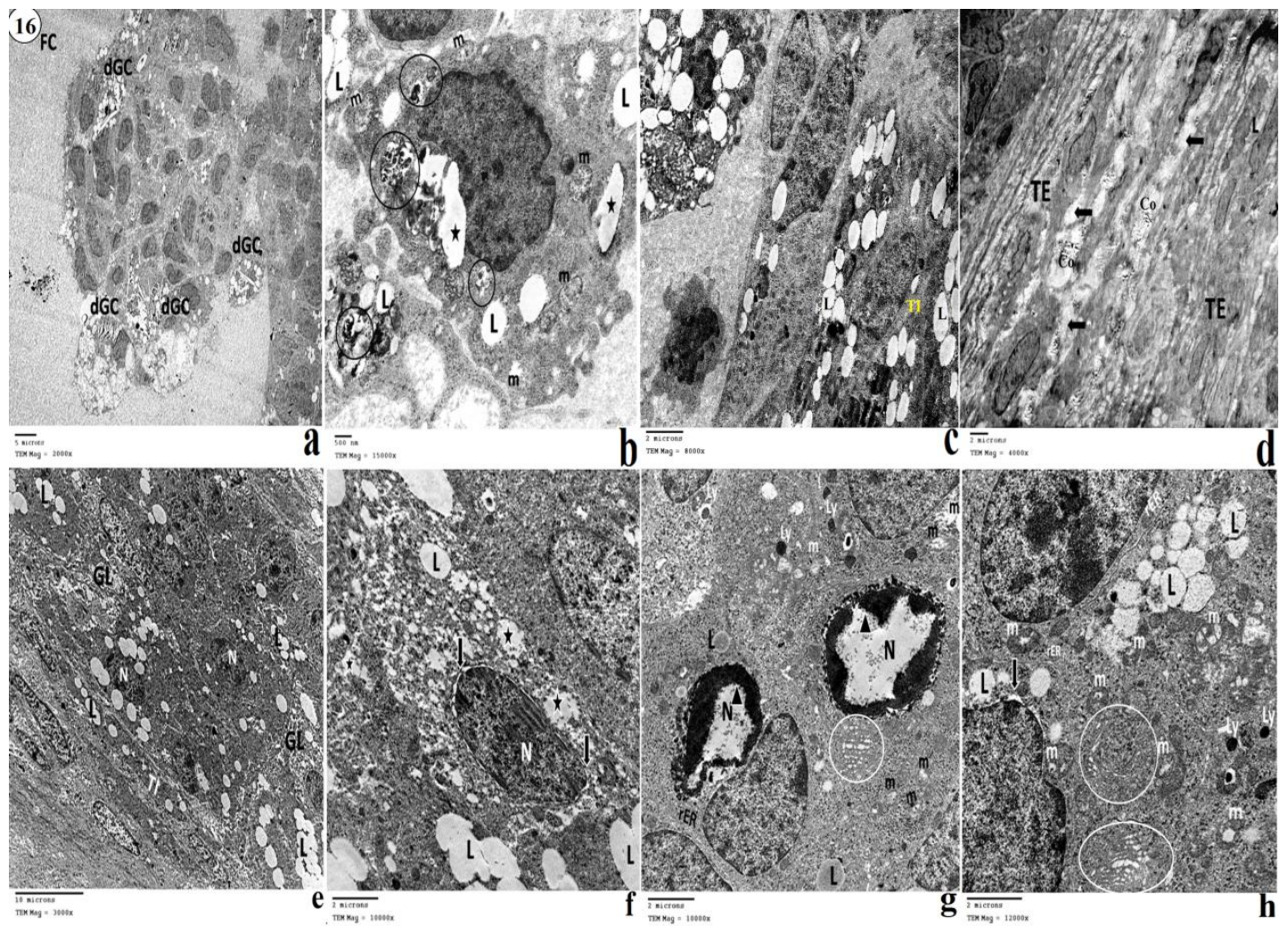

Figure (16): Electron photomicrographs from the letrozole-induced PCO group: (a-c) Follicular cyst (FC), degenerated granulosa cells (dGC) spilled in the antrum, electronlucent and electron-dense lipid droplets (L). (b) Swollen mitochondria (m) with disrupted cristae, empty spaces (star) and multivesicular bodies enclosed electron opaque material (circles) in the cytoplasm of degenerated granulosa cells. (c) Degenerated theca interna (TI) contained numerous lipid droplets (L). (d) Expanded intercellular spaces (arrows) between theca externa cells (TE) as well as collagen fibers (Co) cut in different directions. (e) Degenerated corpus luteum had numerous variable-sized electron lucent lipid droplets (L) in the cytoplasm of granulosa lutein cells (GL) and theca interna cells (TI). (f) Granulosa lutein nucleus $(\mathrm{N})$ with dilated perinuclear cisternae (arrows), areas of rarified cytoplasm (stars), and numerous variable-sized electron lucent lipid droplets (L). (g, h) Deformed nuclei $(\mathrm{N})$ with margination of condensed chromatin clumps (arrowheads), lipid droplets (L), abnormal swollen mitochondria with disrupted cristae, lysosomes (Ly), dilated Golgi apparatus (circle) and sparse of the rough endoplasmic reticulum (rER) as well as increased spacing of nuclear envelope (arrows) (TEM a x2000; b x15000; c x8000; d x4000; e x3000; f, g x10000 and h x12000). 


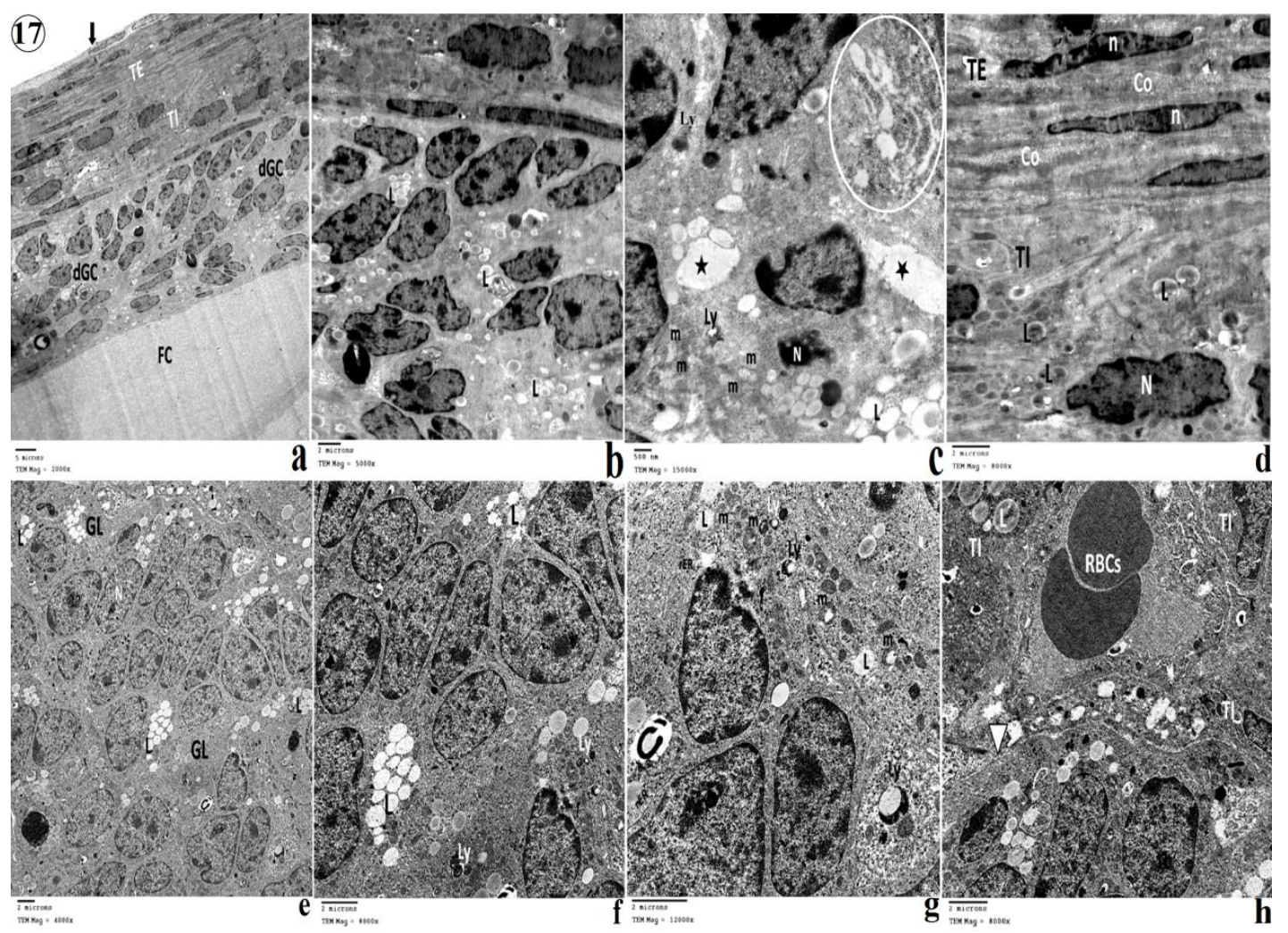

Figure (17): Electron photomicrographs from the recovery group: (a, b) Flattened surface epithelium (arrow), follicular cyst (FC), degenerated granulosa cells (dGC) with numerous electron lucent lipid droplets (L), polygonal theca interna cells (TI) and flattened theca externa cells (TE). (c) Pyknotic nuclei (N), electron-lucent lipid droplets (L), degenerated mitochondria (m) with deteriorated cristae, lysosomes (Ly), empty spaces (star) and dilated Golgi complex (circles) within the cytoplasm of the degenerated granulosa cells. (d) Theca interna cells (TI) with euchromatic oval nuclei (N) and lipid droplets (L). Flattened theca externa cells (TE) with elongated flattened nuclei (n) as well as collagen fibers (Co) cut in different directions. (e-g) Degenerated granulosa lutein cells (GL) of the corpus luteum had variable-sized electron lucent lipid droplets (L), lysosomes (Ly) and degenerated mitochondria (m) with disrupted cristae. (h) Electron lucent lipid droplets (L) in the cytoplasm of the degenerated theca interna cells (TI) enclosed blood capillary contained red blood corpuscles (RBCs) and separated from the granulosa lutein cells by a basal lamina (arrowhead) (TEM a x2000; b x5000; c x15000; d, f, h x8000; e x4000 and g x12000). 


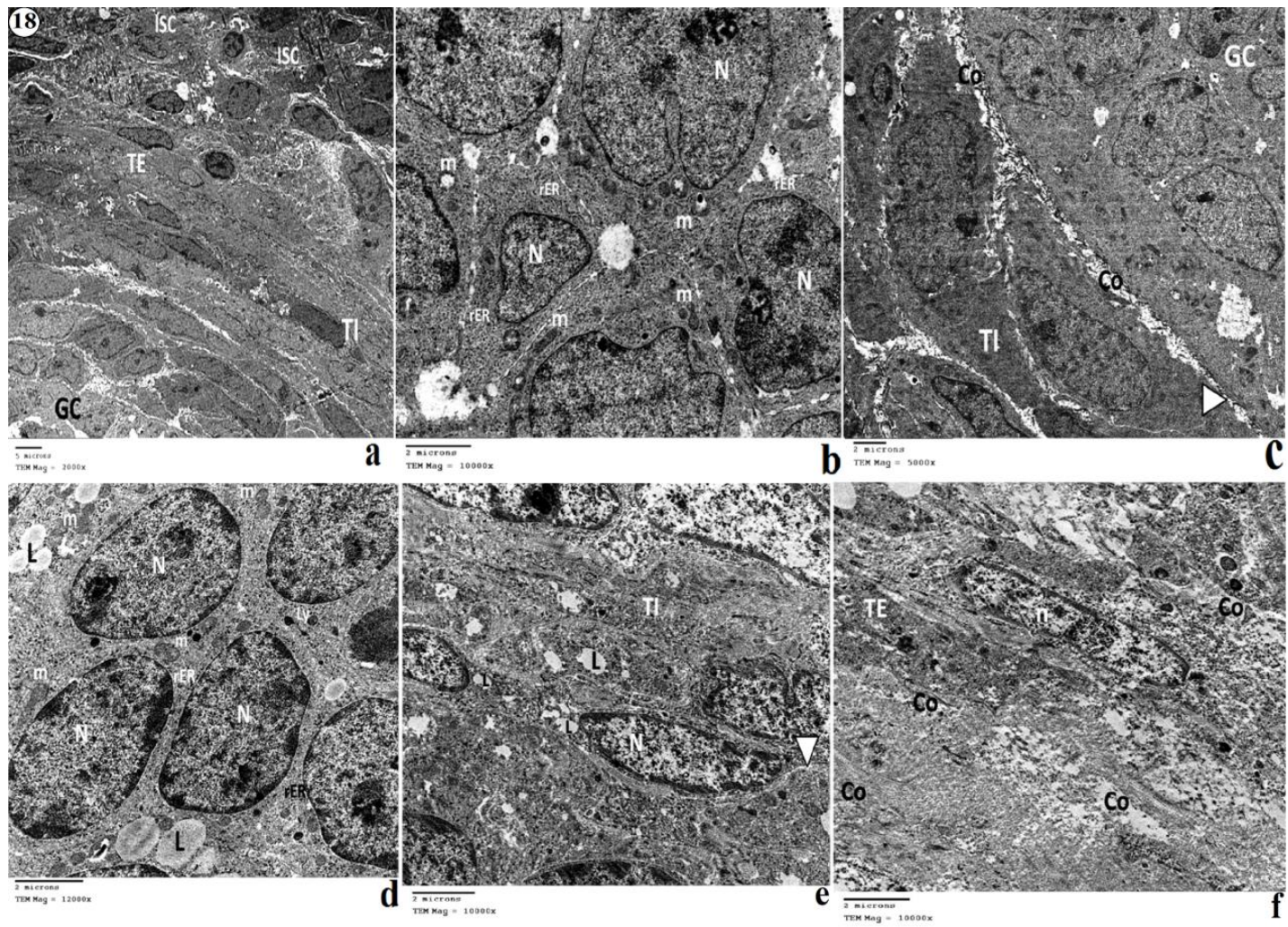

Figure (18): Electron photomicrographs from the ovary of the flaxseed-treated group: (a) Polyhedral granulosa cells (GC) of a secondary ovarian follicle surrounded by oval theca interna cells (TI), flattened theca externa cells (TE) and polyhedral interstitial cells (ISC). (b) Granulosa cells had euchromatic nuclei $(\mathrm{N})$, oval or elongated mitochondria $(\mathrm{m})$ with tubular cristae and sparse of the rough endoplasmic reticulum (rER). (c) Basal lamina (arrowhead) as well as a thin layer of collagen fibers (Co) cut in different directions, separated granulosa cell layer (GC) from surrounding theca interna (TI). (d) Large polyhedral granulosa lutein cells of corpus luteum had euchromatic nuclei $(\mathrm{N})$, mitochondria $(\mathrm{m})$ with tubular cristae, scanty of the rough endoplasmic reticulum (rER), lysosomes (Ly) and few-electron lucent lipid droplets (L) in the cytoplasm. (e) Basal lamina (arrowhead), theca interna (TI) had euchromatic oval nuclei (N) and few lipid droplets (L). (f) Theca externa cells (TE) with flattened nuclei (n) as well as collagen fibers (Co) cut in different directions in between theca externa of the corpus luteum (TEM a x2000; b x10000; c x5000; d x12000 and e, f x10000).

\section{Histo-morphometric results:}

Regarding the histomorphometric results, the statistical comparison between the control (GI) and the combined flaxseed+letrozole group (GIII) revealed no significant difference among them ( $>>0.05)$.

A significant decrease in the mean number of the primordial, primary, preantral, antral follicles and corpora lutea were detected in the letrozole inducedPCO (GII) and recovery (GV) groups in $\mathrm{H} \& \mathrm{E}$ stained sections $(\mathrm{P}<0.001$ versus the control group). The number of cystic follicles in both groups increased significantly compared to the control group which showed the absence of cystic follicles. Inversely, administration of 


\section{0}

MONA M. ABD EL-GALIL AND SHYMAA FATHY MOHAMED

aqueous flaxseed extract (GIII and GV) ameliorated the destructive effect of letrozole on the ovarian tissue as demonstrated by a significant increase in the mean number of growing follicles and corpora lutea coupled with a significant decrease in the mean number of cystic follicles in comparison with the letrozole induced-PCO and recovery groups $(\mathrm{P}<$ 0.001), (Table 4\& Histogram 1). However, most of these values could not reach the control values in the flaxseed treated group.

The letrozole induced-PCO (GII) and recovery $(\mathrm{GV})$ groups revealed a significant decrease in the mean thickness of the granulosa cell layer of the antral and cystic follicles coupled with a significant increase in the mean thickness of the theca cell layer when compared to the control group ( $\mathrm{P}<0.001)$. Interestingly, improvement was more pronounced in the combined flaxseed and letrozole group (GIII) than the flaxseed treated group $(\mathrm{GV})$. The former revealed nearly normal values when compared to the letrozole induced-PCO group $(\mathrm{P}<$ 0.001 ), while the latter did not return to the normal values with a significant difference in comparison to the recovery group ( $\mathrm{P}<0.001)$ (Table 4).

Interestingly, there was a statistically significant increase in the area percentage of collagen in Masson's trichrome stained sections in the letrozole-induced PCO and recovery groups that recorded the highest mean value when compared to the control rats $(\mathrm{P}<0.001)$. Inversely, the flaxseed administered groups (GIII and GV) displayed a statistically significant decrease in the mean area \% of collagen as compared to the letrozole induced-PCO and recovery groups respectively $(\mathrm{P}<$ $0.001)$. However, the improvement could not reach the control values in the flaxseed treated group as there was a significant difference when compared to the control group $(\mathrm{P}<0.05) \quad($ Table 4 , Histogram 2).

Table (4): One-way ANOVA followed by post hoc Tukey's comparative statistical analysis of the mean number of ovarian follicles (/ field), thickness of granulosa cell and theca cell layers, and the mean area $\%$ of collagen in rats of different groups

\begin{tabular}{|c|c|c|c|c|c|c|}
\hline Parameters & $\begin{array}{c}\text { Control } \\
(\mathrm{n}=6)\end{array}$ & $\begin{array}{l}\text { letrozole- } \\
\text { induced } \\
\text { PCO }(n=6)\end{array}$ & $\begin{array}{c}\text { Flaxseed+ } \\
\text { Letrozole } \\
\quad(n=6)\end{array}$ & $\begin{array}{c}\text { Recovery } \\
(\mathbf{n}=6)\end{array}$ & $\begin{array}{c}\text { Flaxseed } \\
\text { treated } \\
(\mathbf{n}=6)\end{array}$ & $\boldsymbol{P}$ \\
\hline Primordial Follicles & $22.5 \pm 1.1$ & $5.8 \pm 1.2^{\mathrm{a}^{*}}$ & $21.3 \pm 1.4^{b^{*}}$ & $4.6 \pm 1.1^{a^{*}}$ & $16.3 \pm 1.9^{\mathrm{a}^{*} \mathrm{c}^{*}}$ & $<0.001$ \\
\hline Primary follicles & $10.8 \pm 0.5$ & $3.0 \pm 0.7^{a^{*}}$ & $10.3 \pm 1.2^{b^{*}}$ & $2.8 \pm 0.6^{a^{*}}$ & $9.4 \pm 0.5^{c^{*}}$ & $<0.001$ \\
\hline Preantral follicles & $9.8 \pm 1.3$ & $4.3 \pm 0.8^{\mathrm{a}^{*}}$ & $9.2 \pm 1.0^{b^{*}}$ & $3.8 \pm 0.9^{a^{*}}$ & $7.5 \pm 1.4^{\mathrm{a}^{*} \mathrm{c}^{*}}$ & $<0.001$ \\
\hline Antral follicles & $7.5 \pm 0.8$ & $2.1 \pm 0.4^{\mathrm{a}^{*}}$ & $6.8 \pm 0.9^{b^{*}}$ & $1.8 \pm 0.3^{\mathrm{a}^{*}}$ & $6.1 \pm 0.5^{\mathrm{a} * c^{*}}$ & $<\mathbf{0 . 0 0 1}$ \\
\hline Corpus follicles & $5.7 \pm 0.5$ & $2.2 \pm 0.6^{\mathrm{a}^{*}}$ & $5.2 \pm 0.7^{b^{*}}$ & $2.0 \pm 0.5^{a^{*}}$ & $4.8 \pm 0.8^{\mathrm{a}^{* \mathrm{c}^{*}}}$ & $<0.001$ \\
\hline Cystic follicles & $0.00 \pm 0.0$ & $8.1 \pm 0.7^{a^{*}}$ & $0.00 \pm 0.0^{b^{*}}$ & $8.3 \pm 0.8^{\mathrm{a}^{*}}$ & $1.2 \pm 0.3^{\mathrm{a}^{*} \mathrm{c}^{*}}$ & $<0.001$ \\
\hline $\begin{array}{c}\text { Granulosa cell } \\
\text { layer thickness }(\mu \mathrm{m})\end{array}$ & & & $49.8 \pm 2.6^{b^{*}}$ & $24.5 \pm 2.6^{\mathrm{a}^{*}}$ & $38.5 \pm 1.9^{\mathrm{a}^{*} \mathrm{c}^{*}}$ & $<0.001$ \\
\hline $\begin{array}{l}\text { Theca cell layer } \\
\text { thickness }(\mu \mathrm{m})\end{array}$ & $17.3 \pm 1.2$ & $38.5 \pm 1.9^{\mathrm{a}^{*}}$ & $19.3 \pm 1.8^{b^{*}}$ & $36.7 \pm 2.8^{a^{*}}$ & $25.5 \pm 0.8^{\mathrm{a}^{*} \mathrm{c}^{*}}$ & $<0.001$ \\
\hline $\begin{array}{c}\text { Collagen fiber area } \\
(\%) \text { in the ovarian } \\
\text { medulla }\end{array}$ & $7.3 \pm 1.2$ & $14.5 \pm 0.4^{\mathrm{a}^{*}}$ & $7.9 \pm 0.8^{b^{*}}$ & $15.6 \pm 0.5^{a^{*}}$ & $9.4 \pm 0.8^{\mathrm{a}^{*} \mathrm{c}^{*}}$ & $<0.001$ \\
\hline
\end{tabular}

All results were expressed as mean \pm SD; SD: standard deviation; $\mathrm{n}$ : number of rats; *P < 0.05 "significant"

${ }^{\text {a }}$ significant versus control group

${ }^{\mathrm{b}}$ significant versus letrozole-induced PCO group

${ }^{\mathrm{c}}$ significant versus recovery group 


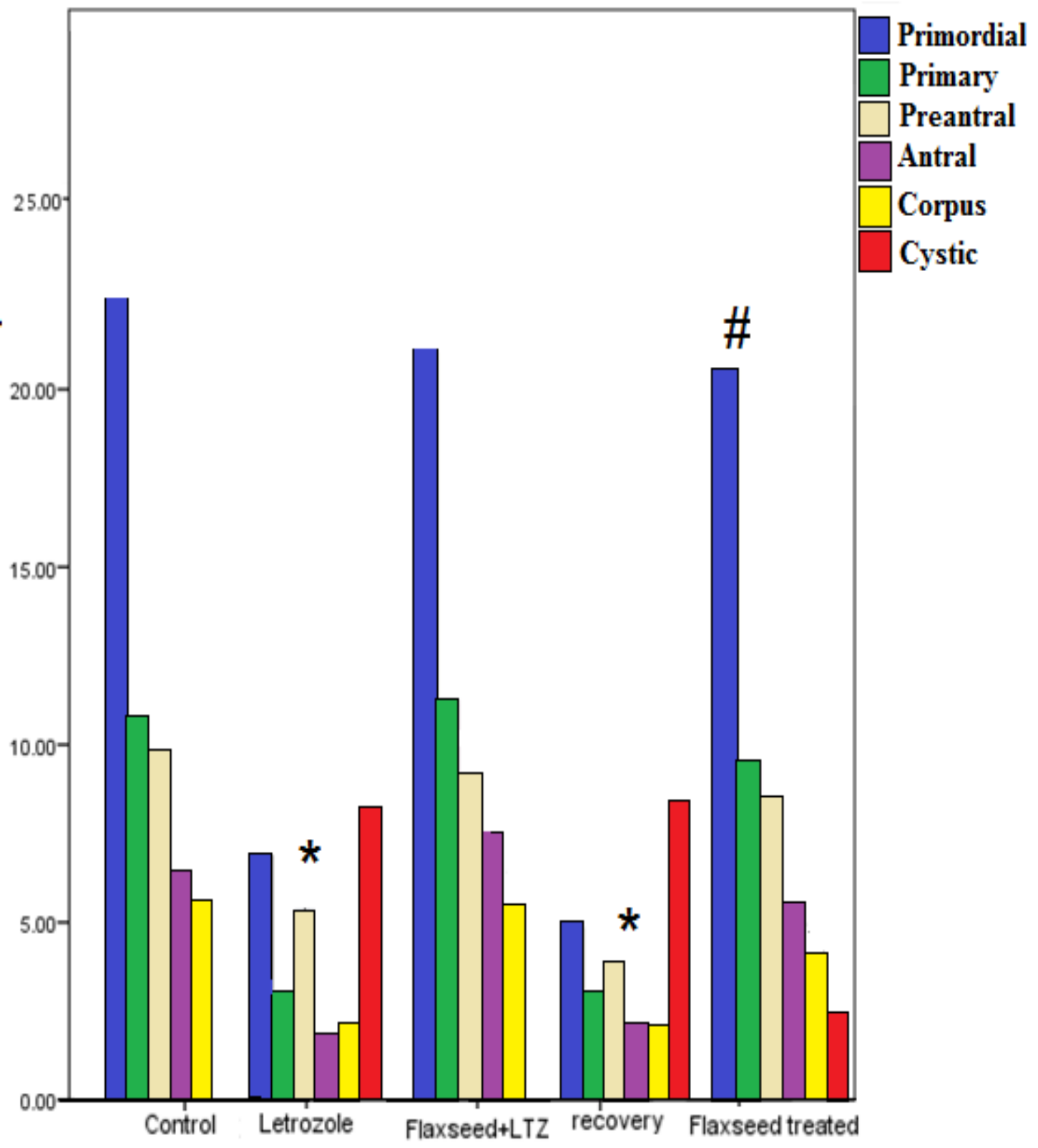

Histogram (1): Mean numbers of ovarian follicles (/field) in H\&E stained section in the different expermental groups.

*Significant versus control group:

\#Significant versus polycystic ovary group. 


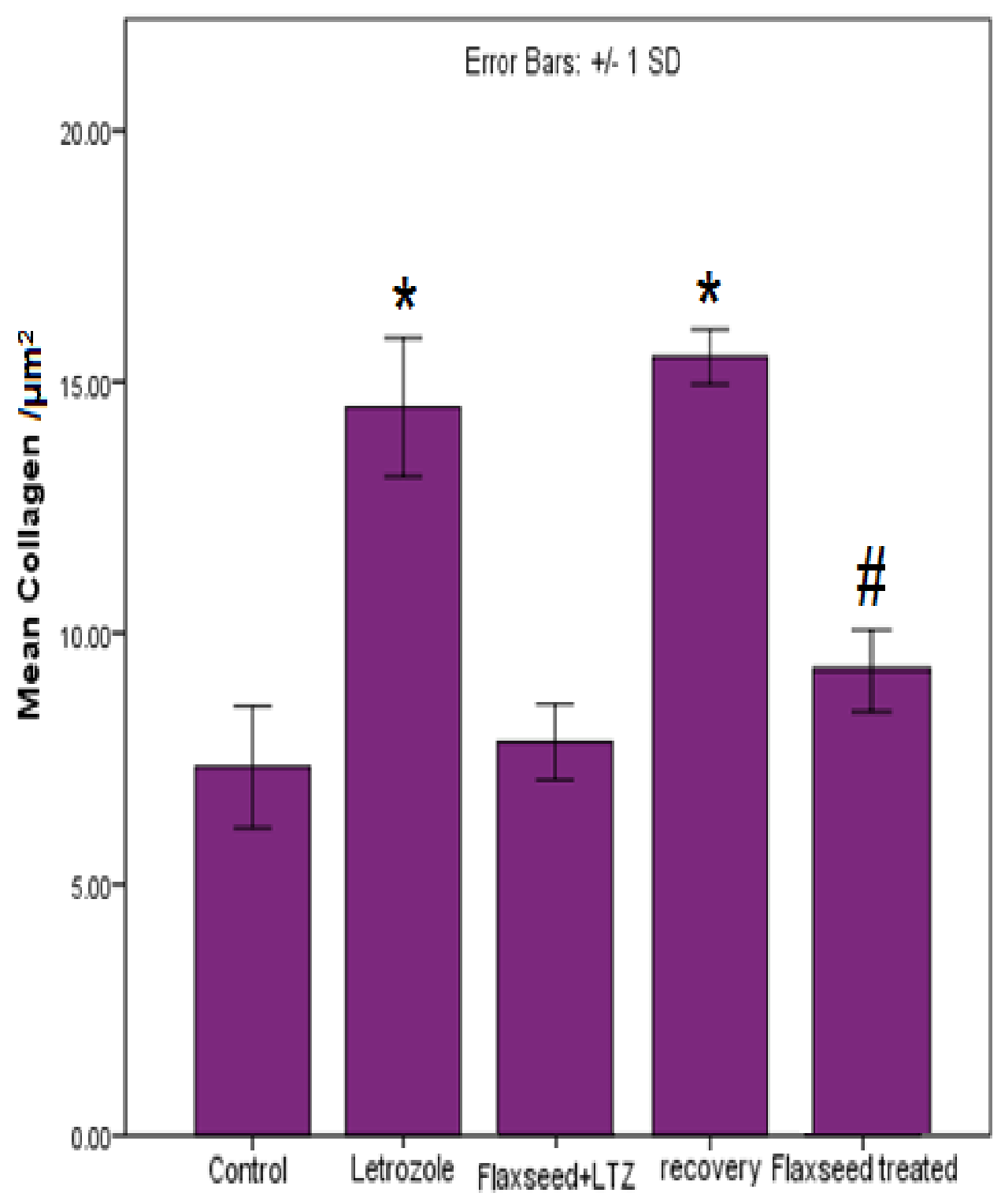

Histogram (2): The mean area percentage of collagen fibers in ovarian medulla in Masson's trichrome stained sections in the different experimental groups.

*Significant versus control group

\#Significant versus polycystic ovary group. 


\section{DISCUSSION}

Polycystic ovary syndrome (PCOS) has been considered as one of the most controversial syndromes in gynecology and endocrinology. Hyperandrogenism and anovulation are typical clinical features of PCOS (Azziz et al., 2016). Excessive androgen can cause early luteinization of ovarian granular layer cells, stopping follicular development, leading to follicle atresia and eventually anovulation or poor ovulation (Palomba et al., 2017).

Letrozole, a non-steroidal aromatase inhibitor, blocks the conversion of androgens into estrogen thereby efficiently decreasing the estrogen/androgen ratio in the follicular fluid causing hormonal imbalance and circulating hyperandrogenism leading to abnormal follicular development and inducing comprehensive reproductive and metabolic phenotypes of human PCOS (Kauffman et al., 2015).

Treatment modalities for PCOS are difficult because of its complex etiology and pathogenesis as well as its polymorphic clinical manifestations (Jadhav et al., 2013). However, regulating abnormal androgen and/or estrogen is an effective means of treating PCOS (Daneasa et al., 2016).

Natural herbal remedies capable of modifying PCO with few or no side effects have become more popular, cheaper, and appealing to patients. Linumusitatissimum L (flaxseed), the richest known source of $\alpha$-linolenic acid, omega-3 fatty acid, lignans, and dietary fiber have attracted a great deal of interest among consumers and health care professionals for their potential benefits on human health (Kroliczewska et al., 2018).

Accordingly, the present study was designed to clarify the effects of consuming flaxseed on improving blood glucose level, inflammatory cytokines, total antioxidant capacity, sex hormone levels and ameliorating the histological changes in the ovary of letrozole - induced PCOS rat model.

Rezvanfar et al. (2012) and Padmanabhan \& Veiga-Lopez (2013) established their rat model of PCO by using a minimum dose of letrozole 3 $\mathrm{mg} / \mathrm{kg}$ bodyweight for 3 weeks during which the key features of PCOS included obesity, altered glucose tolerance, hyperandrogenism and cystic follicle formation was induced, indicating the successful establishment of our model.

In the present study, letrozole advanced to a significant increase in the final body weight, ovarian weight and blood glucose level concomitant with a significant increase in the serum cytokine; tumor necrosis factor-alpha (TNF- $\alpha)$ and the oxidative stress marker; malondialdehyde (MDA) coupled with a significant decrease in total antioxidant capacity (TAC) that was reported in the letrozole-induced PCO and the recovery groups (GII, GIV) in comparison with the control group (GI).

As regarding the serum sex hormones levels, the letrozole groups (GII and GIV) encountered a statistically significant increase in the serum testosterone and LH levels coupled to a decrease in both estradiol and progesterone comparable to 


\section{${ }^{3084}$ MONA M. ABD EL-GALIL AND SHYMAA FATHY MOHAMED}

control. Serum FSH was not significantly different between groups.

This was confirmed by the vaginal smear in the PCOS groups (GII, GIV) that showed an absence of the normal estrous cyclical changes with the abundance of leukocytes which is the predominant cell type in the diestrus phase (pseudo diestrus). This result was parallel to those obtained by Li et al. (2016) and Matsuzaki et al. (2017).

On the contrary, elevated testosterone and LH with no change in the estrogen (E2) has been reported in the study of Matsuzaki et al. (2017) in an experimentally-induced PCOS model. Also, elevation of FSH levels has been reported in the study of Li et al. (2016) in PCO rat models. They attributed these variations to the type of animal used, dose, duration and form of the drug used for the PCOS induction. Elevated testosterone and $\mathrm{LH}$ levels were the main hormonal disorders commonly associated with human PCOS.

The cross-link between the present results could explain the mechanism of the changes that occurred in letrozole-induced PCOS. The increase in the body weight and subsequent obesity in Letrozoleinduced PCO rats was explained by the positive correlation between the hyperandrogenemia induced by letrozole and the elevated different cytokines expressions especially serum TNF- $\alpha$ which is an important regulator of adipocyte differentiation and lipid recruitment. Also, hyperandrogenemia disturbed both enzymes and proteins concerned in lipid metabolism with many risks of dyslipidemia in the form of hypertriglycerides, reduced high density lipoprotein (HDL) and increased low density lipoprotein (LDL) (Abdulghani et al., 2012 and Lombardi et al. 2014).

A nasty cycle of insulin resistance (IR) and hyperglycemia ensuing in high levels of androgens and dyslipidemia were also proposed (Sirmans and Pate, 2013 and Conway et al., 2014).

The disturbance in serum cytokines and antioxidant enzymes expression that was reported in the letrozole groups was explained by the elevated serum TNF- $\alpha$ which promoted the synthesis of interleukins (IL-6, IL-8) and are directly chemotactic to the leukocytes concomitant with a massive release of reactive oxygen species (ROS) that are key regulators of inflammatory processes induced during PCOS (Palomo et al., 2015 and Setyaningsih et al., 2015).

Furthermore, the oxidative damage to lipids as a consequence of oxidative stress end to increase the serum MDA which is considered a harmful lipid peroxidation indicator in the pathological process of letrozole-induced PCO reflecting impaired cell wall permeability and integrity (Cohen et al., 2013 and Norouzi et al., 2016).

Hyperandrogenmia following letrozole in PCO groups (GII and GIV) was related to the potent effect of letrozole in blocking aromatization of testosterone to estradiol which causes elevated androgen levels, although not always, an elevated LH: FSH ratio (Goodarzi et al., 2015 and Jelodar et al., 2018).

Besides, the elevation of the testosterone and LH levels could be linked to the elevated serum cytokines and hyperglycemia concomitant with using 
letrozole. This seemed to decrease the negative feedback tone and disturbed the delicate balance of the hypothalamicpituitary-ovarian (HPO) axis resulted in frequent excitation of hypothalamic neurons, thereby promoting frequent pulsatile gonadotrophin-releasing hormone $(\mathrm{GnRH}) / \mathrm{LH}$ secretion, and increases LH/FSH ratio. Consequently, abnormally high LH promotes excess androgen production by ovarian theca interna cells and induces apoptosis in granulosa cells of ovarian follicles ending in the polycystic ovary (Palomo et al., 2015 and Matsuzaki et al., 2017).

Dumesic et al. (2015) and Hurliman et al. (2015) reported that hyperglycemia or glucose intolerance may be the key indirect mediator that suppresses hepatic sex hormone-binding globulin synthesis (SHBG). This results in increased serum levels of unbound steroid hormones and modulates the activity of the key regulatory enzyme of androgen biosynthesis, P450c17 in the theca interna and interstitial cells ensuing in hyperandrogenism in PCO women.

These biochemical parameters were well correlated with the ovarian histological results that confirmed stromal and follicular degeneration in the letrozole-induced PCO group with numerous cystic follicles, desquamated granulosa cells with vacuolated cytoplasm and pyknotic nuclei, vacuolated corpora lutea and dilated congested blood vessels within the ovarian medulla. This was confirmed statistically by a decrease in the number of the different growing follicles, corpora lutea and the mean thickness of granulosa cell layer as well as a significant increase in the number of cystic follicles and thickness of theca interna cells layer.

The Masson's trichrome stained sections of the PCO group revealed increased density and distribution of collagenous fibers within the ovarian medulla that was confirmed by an increase in the area percentage of collagen fibers in the morphometric analysis as compared to the control group.

These degenerative changes in the letrozole-induced PCO groups were confirmed by the electron microscopic observations of a follicular cyst with cytoplasmic degeneration that contained numerous variable-sized electron lucent lipid droplets, multivesicular bodies, and pyknotic nuclei. Moreover, corpus luteium showed deformed granulosa lutein cells, abnormal organelles, mitochondrial swelling, broken or even disappeared mitochondrial cristae, dilated endoplasmic reticulum and dilated Golgi complex on comparison with the control group.

All the previous histological changes were indicative of the presence of biologically active levels of LH, androgens and lack of interplay between granulosa and theca cells ending in the cardinal feature of PCOS (Palomo et al., 2015 and Tahmasebi et al., 2015). As the follicle enlarges, the granulosa cell layer undergoes atresia, becomes apoptotic, progressively degenerative and dwindles in number and in their entire structure. By contrast, the theca cell layer is considerably hyperplastic luteinized cells and is responsible for increased androgen production 2-3-folds compared with those of the normal ovary, creating a large number of peripherally located thinwalled cysts under an ovarian capsule 


\section{MONA M. ABD EL-GALIL AND SHYMAA FATHY MOHAMED}

(Richards et al., 2018). Besides, Sun et al. (2013) suggested that the formation of a "hyperplastic" theca interna reflects the addition of luteinized granulosa cells in the cyst wall rather than true hyperplasia.

Gambineri et al. (2012) and Sorour et al. (2017) have pinpointed "selective insulin resistance" theory as the fundamental link explaining the pathogenesis of PCOS, where insulin resistance state, enhances the bioactivity of insulin-like growth factor-binding protein-1 (IGF-I), rapidly and completely result in higher circulating and intraovarian availability of free insulinlike growth factors (IGFs), which in turn is a potent stimulator of LH-induced androgen synthesis by ovarian interstitial cells. This may contribute to further hyperandrogenism ending in the arrest of follicular development, chronic anovulation and cystogenesis.

In addition, the degenerative changes in letrozole-induced PCO groups were explained on the bases of long-lasting status of oxidative/ nitrosative stress and insufficient antioxidant activity as a consequence of hyperglycemia and hyperandrogenemia with the overexpression of several proinflammatory cytokines such as nuclear transcription factor-Kappa-B (NF-kB), TNF- $\alpha$ and IL-6. This leads to progressive ovarian cystogenesis, correlates with poor oocyte quality, oxidative DNA damage of granulosa cells, drastically impaired mitochondrial $\beta$-oxidation via changing the mitochondrial inner membrane composition, translocation of intramitochondrial protein (apoptosis-inducing factor), decreasing in the proton leak. This could damage mitochondrial DNA directly with ATP depletion and induce mitochondrial permeability of cytochrome $\mathrm{C}$ and progressive mitochondrial damage leading to lipid peroxidation of biological membranes ending with apoptosis dysregulation, atrophic degeneration, follicular atresia and cell lysis (Lombardi et al., 2014 and Tahmasebi et al., 2015).

The dilated Golgi complexes observed in the present study are typical alterations of an activated steroidogenic cell which is related to enhance the secretory cell function (Seto-Young et al., 2010 and Sorour et al. (2017). The multivesicular lysosomal accumulations seem to be an obligatory intermediate step in the degradation of damaged portion, trafficking necrotic debris, and many other ligands causing their intra lysosomal accumulation (Xu and Ren, 2015).

The increased density and distribution of the collagen fibers within the ovarian medulla in the present study were in agreement with Sorour et al. (2017) who stated that fibrosis is simply the consequences of inflammation that associated with the production of reactive oxygen species, increase levels of proinflammatory cytokines such as TNF$\alpha$, C-reactive protein, tissue plasminogen activator (t-PA), transforming growth factor (TGF- $\alpha$ or $-\beta$ ), activator protein-1 (AP-1) and nuclear transcription factorKappa-B (NF-kB) with decreased levels of anti-inflammatory cytokines.

In the present study, the natural recovery group (GIV) did not restore the histological findings compared to the control group that was confirmed by the insignificant difference between the recovery and the letrozole-induced PCO groups in all biochemical and 
histomorphometric changes. This may be attributed to the non-sufficient recovery period to restore the histological findings (Jadhav et al., 2013).

Fortunately, administration of flaxseed extracts either concomitantly with letrozole (GIII) or as a therapeutic agent after induction of PCOS $(\mathrm{GV})$ revealed great improvement in all the measured parameters and ameliorated the histological changes in the ovarian tissues. This improvement was more pronounced in the combined flaxseed and letrozole group (GIII), which returned nearly back to normal.

Flaxseed groups (GIII and GV) revealed a significant decrease in the body and ovarian weights with marked improvement in the blood glucose levels. Meanwhile, both groups showed a significant reduction in the TNF- $\alpha$ and MDA levels coincided with a significant elevation in the TAC in comparison to the $\mathrm{PCO}$ rats.

Reduction in the bodyweight upon flaxseed administration in GIII, GV could be explained by the lecithin water-soluble fibers and alpha-linolenic acid constituents in flaxseed, where lecithin dissolves the nasty fats from food in the digestive tract and taken them to be eliminated from the body, rather than being stored as body fat. Water-soluble fibers and protein contents of flaxseed are slowly digested, delay gastric emptying, and gives a feeling of fullness for a longer time and contribute to suppressing appetite. The alpha-linolenic acid increases the body's sensitivity to the leptin hormone, which contributes to reducing feeding behavior, stimulate thyroid function, and thus speeds up metabolism and also possibly increases thermogenic activity in brown adipose tissue (Carotenuto et al., 2013 and Bernacchia et al., 2014).

The hypoglycemic effect of flaxseed was attributed to the high lignan constituent with potential antioxidant efficiency that enhances peripheral insulin sensitivity, decreased gluconeogenesis and glycogenolysis (Imran et al., 2015 and Maghsoudi, 2016). Also, dietary watersoluble fibers contents in flaxseed activate the extracellular signal-regulated kinase pathway to control the secretion of a glucagon's-like peptide-1, thereby enhancing the insulin secretion, improve insulin action by increasing glucose transport and correct the hyperglycemia which is linked to insulin resistance in PCO (Tharwat et al., 2017).

The antioxidant, anti-inflammatory and anti-apoptotic effects of flaxseed could be related to its high contents of vitamin $\mathrm{E}$, $\alpha$-linolenic acid or omega-3 fatty acids, flavonoids and phenolics of flax lignan complex, with the highest activity in scavenging superoxide radicals and other reactive oxygen species (ROS) via acting on both the cyclooxygenase and lipoxygenase pathways, thereby strengthening the endogenous antioxidant defense system that can confer protection on inflammatory/immune cells, disrupt intrinsic and extrinsic cell death pathways so protecting cells from apoptosis induced by oxidative stress in the PCOS rats (Abidi et al., 2016 and Tharwat et al., 2017).

In addition, flaxseed revealed an improvement in the serum sex hormone levels, where levels of testosterone and LH decreased tremendously coupled with 


\section{MONA M. ABD EL-GALIL AND SHYMAA FATHY MOHAMED}

increased estrogen and progesterone levels when compared to PCO groups.

The vaginal smear in flaxseed groups showed restoration of the normal cyclical changes as in the control group. The estrous cycle is formed of four phases, namely proestrus, estrus, metestrus and diestrus and lasts for 4 to 5 days (Hong et al., 2010). The proestrus phase corresponds to the human follicular stage, which is associated with a rise in circulating estradiol concentrations and little surge in prolactin, this leads to a rise in LH and FSH release. The peak in FSH concentration with an associated rapid decline in estradiol levels signals ovulation and entry into the estrus phase. Metestrus and diestrus are homologous to human early and late secretory stages of the reproductive cycle, respectively, with high levels of progesterone (McLean et al., 2012 and Ayodeji \& Akhigbe, 2020).

The presence of the previous 4 phases enabled us to measure the sex hormones level in the estrus stage of the cycle, where the smear in the estrous phase showed large, angular and irregularly shaped epithelial keratinocytes (DiamantiKandarakis et al., 2012).

The anti-androgenic effect of flaxseed is mainly related to lignan contents that may raise sex hormone-binding globulin (SHBG) production which have a profound impact in reducing the excess testosterone and androgen levels thus suppressing androgen-mediated alterations in the ovary, inhibiting the apoptosis pathway and improving ovarian folliculogenesis (Hendawi et al. 2016).

The potential effect of the flaxseed extract is emphasized by the improvement in ovarian histological structure in the flaxseed groups (GIII and GV) as evident by improving polycystic ovarian morphology that was confirmed by a significant increase in the total number of growing follicles including primary, preantral, antral follicles and corpora lutea, with decreasing the number of cystic follicles as compared to the PCO rats. Degenerative changes were mildly noticed in corpora lutea of flaxseed groups as evident by increased thickness of the granulosa cell layer coupled with the decreased thickness of the theca cell layer as compared to the PCOS group. However, vacuolations of few granulosa lutein cells and congested vessels were still observed in the ovarian stroma. Moreover, flavenoid decrease levels of procollagen type I, III and thus reduces collagen distribution and fibrogenesis (Kadhim, 2017). This was in line with the decreased collagen area percentage within the ovarian medulla on flaxseed administration as compared to the PCO groups (Banitalebi et al., 2016).

\section{CONCLUSION AND RECOMMENDATION}

Flaxseed could efficiently alleviated the ovarian damage and restored ovarian function in a letrozole-induced PCO rat model with the ability to combat metabolic and endocrine comorbidities as proved in the present study correlated with biochemical, histological and morphometric results that may be ascribed to the direct antioxidant, free radical scavenging activities, anti-inflammatory properties, anti-apoptotic activities, and a powerful flavonoid. However, conclusive evidence regarding absolute therapy could not be obtained in this study. Further experiments on animals and clinical trials 
are needed to determine whether flaxseed can be applied as an adjunct therapy or alone as a curative of PCO as shown in this preclinical study and further research is needed to determine optimal timing and dosage of flaxseed related to fertility with underlying pathogenic mechanisms.

\section{Funding:}

This research work did not receive any fund or specific grant from funding agencies in the public, commercial, or notfor-profit sectors.

\section{Conflict of interest:}

There is no conflict of interest.

\section{REFERENCES}

1. Abdulghani M, Hussin AH, Sulaiman SA and Chan KL. (2012): The ameliorative effects of Eurycomalongifolia Jack on testosterone-induced reproductive disorders in female rats. Reprod Biol., 12(2): 247-255.

2. Abidi A, Serairi R, Kourda N, Ben Ali R, Ben Khamsa $S$ and Feki M. (2016): Therapeutic effect of flaxseed oil on experimental pulmonary fibrosis induced by bleomycin in rats. European Journal of Inflammation, 14(2): 133-143.

3. Ahmad N, Rahman ZU, Akhtar N and Ali S. (2012): Effects of Aqueous Methanolic Extract of Flax Seeds (Linum Usitatissimum) on Serum Estradiol, Progesterone, Kidney and Liver Functions and Some Serum Biochemical Metabolites in Immature Female Rats. Pak Vet J., 32(2): 211-215.

4. Atilgan R, Kuloglu T, Boztosun A, Orak U, Baspinar M, Can B and Sapmaz E. (2015): Investigation of the effects of unilateral total salpingectomy on ovarian proliferating cell nuclear antigen and follicular reserve: experimental study. Eur J Obstet Gynecol Reprod Biol., 188: 56-60.

5. Ayodeji A F and Akhigbe R E. (2020): Staging of the estrous cycle and induction of estrus in experimental rodents: an update. Fertil Res Pract., 6(5): 1-12.
6. Azziz R, Carmina E, Chen Z, Dunaif A, Laven JS, Legro RS, Lizneva D, NattersonHorowtiz B, Teede HJ and Yildiz BO. (2016): Polycystic ovary syndrome. Nat Rev Dis Primers, 2(1) Suppl.16057: 1-18.

7. Bancroft JD and Layton C. (2013): The hematoxylin and eosin, connective mesenchymal tissues with their stains. In: Suvarna SK, Layton C and Bancroft JD editors.Bancroft's Theory and practice of histological techniques.7th edition. Churchill Livingstone. Philadelphia. PP: 173-212 and 215-238.

8. Banitalebi E, Razavi $T$, Norian $M$ and Laleh B. (2016): The effect of combined aerobic exercise training and green tea extract on serum TNF- $\alpha$ and IL-6 levels in obese women with type 2 diabetes. Daneshvar Med., 23(123): 11-20.

9. Bernacchia R, Preti R and Vinci G. (2014): Chemical Composition and Health Benefits of Flaxseed. Austin J Nutri Food Sci., 2(8): 1045.

10. Carotenuto F, Minieri M, Monego G, Fiaccavento R, Bertoni A, Sinigaglia F, Vecchini A, Carosella $L$ and Nardo PD. (2013): A diet supplemented with ALA-rich flaxseed prevents cardiomyocyte apoptosis by regulating caveolin-3 expression. Cardiovascular Research, 100: 422-431.

11. Cetisli NE, Saruhan A and Kivcak B. (2015): The effects of flaxseed on menopausal symptoms and quality of life. Holistic Nursing Practice, 29(3): 151-157.

12. Cohen G, Riahi Y, Sunda V, Deplano S, Chatgilialoglu C, Ferreri $\mathbf{C}$, Kaiser $\mathbf{N}$ and Sasson S. (2013): Signaling properties of 4hydroxyalkenals formed by lipid peroxidation in diabetes. Free Radic Biol Med., 65: 978987.

13. Conway G, Dewailly D, DiamantiKandarakis E, Escobar- MorrealeHcF, Franks S, Gambineri A, Pignatelli D, Pugeat $M$ and Yildiz BO. (2014): The polycystic ovary syndrome: a position statement from the European Society of Endocrinology. Eur J Endocrinol., 171 (4): 129. 
14. Cora MC, Kooistra $L$ and Travlos G. (2015): Vaginal Cytology of the Laboratory Rat and Mouse: Review and Criteria for the Staging of the Estrous Cycle Using Stained Vaginal Smears, Toxicologic Pathology, 43(6): 776-793.

15. Daneasa A, Cucolas C, Lenghel LM, Olteanu D, Orasan R and Filip GA (2016): Letrozole vs estradiol valerate induced PCOS in rats: glycemic, oxidative and inflammatory status assessment. Reproduction, 151: 401409.

16. Dewailly D, Lujan ME, Carmina E, Cedars MI, Laven J, Norman RJ and EscobarMorreale HF. (2014): Definition and significance of polycystic ovarian morphology: a task force report from the Androgen Excess and Polycystic Ovary Syndrome Society. Human Reproduction Update, 20(3): 334-352.

17. Diamanti-Kandarakis E, Spritzer PM, SirPetermann T and Motta AB. (2012): Insulin resistance and polycystic ovary syndrome through life. Curr. Pharm. Des., 18(34): 55695576.

18. Dumesic DA, Oberfield SE, Stener-Victorin E, Marshall JC, Laven JS and Legro RS. (2015): Scientific Statement on the Diagnostic Criteria, Epidemiology, Pathophysiology, and Molecular Genetics of Polycystic Ovary Syndrome. Endocr. Rev., 36: 487-525.

19. Elliott KM, Dent J, Stanczyk FZ, Woodley L, Coombes RC, Purohit A and Palmieri C. (2014): Effects of aromatase inhibitors and body mass index on steroid hormone levels in women with early and advanced breast cancer. The British journal of surgery, 101: 939-948.

20. Escobar-Morreale HF. (2018): Polycystic ovary syndrome: definition, etiology, diagnosis and treatment. Nat Rev Endocrinol., 14(5): 270-284.

21. Gambineri A, Patton L, Altieri P, Pagotto U, Pizzi C, Manzoli $L$ and Pasquali $R$. (2012): Polycystic ovary syndrome is a risk factor for type 2 diabetes: results from a longterm prospective study. Diabetes, 61(9): 23692374.
22. Ganorkar PM and Jain RK. (2013): Flaxseed- a nutritional punch. International Food Research Journal, 20(2): 519-525.

23. Ghafurniyan H, Azarnia $M$, Nabiuni $M$ and Karimzadeh L. (2015): The effect of green tea extract on reproductive improvement in estradiol valerate-induced polycystic ovarian syndrome in rat. Iran J Pharm Res., 14(4): 1215-33.

24. Golomb E, Matza D, Cummings CA, Schwalb H, Kodavanti UP, Schneider A, Houminer E, Korach A, Nyska A and Shapira OM. (2012): Myocardial mitochondrial injury induced by pulmonary exposure to particulate matter in rats. Toxicol Pathol., 40:779-788.

25. Goodarzi MO, Carmina $\mathbf{E}$ and Azziz R. (2015): DHEA, DHEAS and PCOS. J Steroid Biochem Mol Biol., 145: 213-25.

26. Hayat MA. (2000): Principles and Techniques of Electron Microscopy: Biological Applications. 4th ed. Cambridge university press, Cambridge, United Kingdom. pp 85-138.

27. Hendawi MY, Alam RTM and Abdellatief SA. (2016): Ameliorative effect of flaxseed oil against thiacloprid-induced toxicity in rats: hematological, biochemical, and histopathological study. Environ Sci Pollut Res., 23: 11855-11863.

28. Ho C, Cacace J and Mazza G. (2007): Extraction of lignans, proteins and carbohydrates from flaxseed meal with pressurized low polarity water. Lebenson Wiss Technol., 40(9): 1637-1647.

29. Hong H, Yen H-Y, Brockmeyer A, Liu Y, Chodankar R, Pike MC, Stanczyk FZ, Maxson $R$ and Dubeau L (2010): Changes in the mouse estrus cycle in response to BRCA1 inactivation suggest a potential link between risk factors for familial and sporadic ovarian cancer. Cancer Research, 70(1): 221-228.

30. Hurliman A, Brown JK, Maille N, Mandala M, Casson $P$ and Osol G. (2015): Hyperandrogenism and insulin resistance, not changes in body weight, mediate the development of endothelial dysfunction in a female rat model of polycystic ovary 
syndrome (PCOS). Endocrinology, 156(11): 4071-4080.

31. Imran M, Ahmad N, Anjum FM, Khan MK, Mushtaq Z, Nadeem $M$ and Hussain S. (2015): Potential protective properties of flax lignin secoisolariciresinol diglucoside. Nutrition Journal, 14 (71): 1-7.

32. Jadhav M, Menon $S$ and Shailajan $S$. (2013): In vivo evaluation of mimosa pudicalinn. In the management of polycystic ovary using rat model. Int. J. App. biol. Pharmaceut. Technol., 4(1): 285-292.

33. Jafarey $R$ and Jaffri SA. (2016): Study on the Estrous Cycle Regularity of Cryopreserved Rat Ovarian Tissues after Heterotopic Transplantation. Open Journal of Obstetrics and Gynecology, 6(5): 293-298.

34. Jangale NM, Devarshi PP, Bansode SB, Kulkarni MJ and Harsulkar AM. (2016): Dietary flaxseed oil and fish oil ameliorates renal oxidative stress, protein glycation, and inflammation in streptozotocin-nicotinamideinduced diabetic rats. J. Physiol. Biochem., 7: 327-336.

35. Jelodar G, Masoomi S and Rahmanifar F. (2018): Hydroalcoholic extract of flaxseed improves polycystic ovary syndrome in a rat model. Iran J Basic Med Sci., 21(6): 645-650.

36. Kadhim EF. (2017): Effect of Flaxseed Application on Bone Healing in Male Rats, Histological and Immunohistochemical Evaluation of Vascular Endothelial Growth Factor. J Med Sci., 17 (2): 81-88.

37. Kafi M, Tamadon A and Saeb M. (2015): The relationship between serum adiponectin and postpartum luteal activity in high producing dairy cows. Theriogenology, 83 (8): 1264-1271.

38. Kauffman AS, Thackray VG, Ryan GE, Tolson KP, Glidewell-Kenney CA, Semaan SJ et al. (2015): A Novel Letrozole Model Recapitulates Both the Reproductive and Metabolic Phenotypes of Polycystic Ovary Syndrome in Female Mice. Biology of Reproduction, 93(3) 69: 1-12.

39. Kheirabad MK, Khodabandeh $\mathrm{Z}$, Rahmanifar F, Tamadon A, Jahromi BN, Owjfard M, Koohi-Hosseinabadi O. (2016):
Testicular germ cells apoptosis following exposure to chronic stress in rats. Asian Pac J Reprod., 5(5): 371-375.

40. Kroliczewska B, Mista D, Ziarnik A, Zuk M, Szopa J, Pecka-Kiełb E, Zawadzki M and Króliczewski J. (2018): The effects of seed from Linum Usitatissimum cultivar with increased phenylpropanoid compounds and hydrolysable tannin in a high cholesterol fed rabbit. Lipids Health Dis., 17(76): 1-14.

41. Legro RS, Arslanian SA, Ehrmann DA, Hoeger KM, Murad MH, Pasquali $R$ and Welt CK. (2013): Diagnosis and Treatment of Polycystic Ovary Syndrome: An Endocrine Society Clinical Practice Guideline. The Journal of Clinical Endocrinology and Metabolism, 98 (12): 4565-4592.

42. Li D, Li C, Xu Y, Xu D, Li HJ, Gao LW, Chen S, Zhang $X$ and Ming H. (2016): Differential expression of microRNAs in the ovaries from a letrozole-induced rat model of polycystic ovary syndrome. DNA Cell Biol., 35(4): 177-183.

43. Liao CH, Lin FY, Wu YN and Chiang HS. (2012): Androgens inhibit tumor necrosis factor-alpha-induced cell adhesion and promote tube formation of human coronary artery endothelial cells. Steroids, 77(7): 75664.

44. Lombardi LA, Simoes RS, Maganhin CC, Baracat MC, Silva-Sasso GR, FlorencioSilva R, Soares JM and Baracat EC. (2014): Immunohistochemical evaluation of proliferation, apoptosis and steroidogenic enzymes in the ovary of rats with polycystic ovary. Rev. Assoc. Med. Bras., 60(4): 349356.

45. Maghsoudi Z. (2016): The role of flaxseed in prevention and management of diabetes mellitus type I and type II. Diab Obes Metab Disor OA., 2: 7-11.

46. Malek-Mohammadi $R$, Roghani $M$ and Salami M. (2015): The effect of aqueous extracts of Melissa officinalis on the oxidative stress indices in the midbrain tissue. FEYZ, 19(1): 8-14

47. Matsuzaki T, Tungalagsuvd A, Iwasa T, Munkhzaya M, Yanagihara R, Tokui T, 
Yano K, Mayila Y, Kato T, Kuwahara A, Matsui S and Irahara M (2017): Kisspeptin mRNA expression is increased in the posterior hypothalamus in the rat model of polycystic ovary syndrome. Endocr J., 64: 7-14.

48. McCann SE, Edge SB, Hicks DG, Thompson LU, Morrison CD, Fetterly G, Andrews C, Clark K, Wilton $J$ and Kulkarni S. (2014): A pilot study comparing the effect of flaxseed, aromatase inhibitor, and the combination on breast tumor biomarkers. Nutrition and Cancer, 66(4): 566-575.

49. McHugh ML. (2011): Multiple comparison analysis testing in ANOVA. Biochemia Medica, 21(3): 203-209.

50. McLean AC, Valenzuela $\mathbf{N}$, Fai $S$ and Bennett AS. (2012): Performing Vaginal Lavage, Crystal Violet Staining, and Vaginal Cytological Evaluation for Mouse Estrous Cycle Staging Identification. J. Vis. Exp., 15(67): e4389-e4399.

51. Medigović IM, Ristić N, Trifunović SL, Manojlović-Stojanoski $M$, Milošević $V$, Zikić D and Nestorović NM. (2012): Genistein affects ovarian folliculogenesis: a stereological study. Microsc Res Tech., 75(12): 1691-1699.

52. Mohammed FSh, El-Stoohy HF, Abd ElSamie AH, El-Bayoumi MM and Rashed AL. (2018): Influence of stem cells and hepatocyte growth factor on aluminum induced central neurotoxicity in rats. QJM: An International Journal of Medicine, 111(12), Suppl.1: i83-i95.

53. Norouzi T, Samani GK, Amini SA, Jafarzadeh $L$ and Mardani G. (2016): Compare the effects of atorvastatin and omega-3 on the index of lipid oxidation in patients with polycystic ovary syndrome. J Shahrekord Univ Med Sci., 18(1): 36-44.

54. Padmanabhan $V$ and Veiga-Lopez A. (2013): Animal models of the polycystic ovary syndrome phenotype. Steroids, 78(8): 734-740.

55. Palomba S, Daolio $J$ and La Sala GB. (2017): Oocyte competence in women with polycystic ovary syndrome. Trends Endocrinol Metab., 28(3): 186-198.
56. Palomo J, Dietrich D, Martin P, Palmer G and Gabay C. (2015): The interleukin (IL)-1 cytokine family - Balance between agonists and antagonists in inflammatory diseases. Cytokine, 76(1): 25-37.

57. Rezvanfar MA, Ahmadi A, Saadi HS, Baeeri $M$ and Abdollahi M. (2012): Mechanistic links between oxidative/nitrosative stress and tumor necrosis factor-alpha in letrozole-induced murine polycystic ovary: biochemical and pathological evidence for the beneficial effect of pioglitazone. Hum. Exp. Toxicol., 31(9): 887-897.

58. Richards JS, Ren YA, Candelaria N, Adams JE and Rajkovic A. (2018): Ovarian follicular theca cell recruitment, differentiation, and impact on fertility: 2017 update. Endocr Rev., 39(1): 1-20.

59. Rizwan S, Naqshbandi A, Farooqui $Z$, KhanAA and Khan F. (2014): Protective effect of dietary flaxseed oil on arsenicinduced nephrotoxicity and oxidative damage in rat kidney. Food Chem.Toxicol., 68: 99107.

60. Seto-Young D, Avtanski D, Strizhevsky M, Parikh G, Patel P, Kaplun J, Holcomb K, Rosenwaks $Z$ and Poretsky L. (2010): Interactions among peroxisome proliferatoractivated receptor- $\gamma$, insulin signaling pathways, and steroidogenic acute regulatory protein in human ovarian cells. J Clin Endocrinol Metab., 92: 2232-2239.

61. Setyaningsih Y, Husodo AH and Astuti I. (2015): Detection of Urinary 8hydroxydeoxyguanosine (8-OHdG) Levels as a Biomarker of Oxidative DNA Damage among Home Industry Workers Exposed to Chromium. Procedia Environ Sci., 23: 290296.

62. Shaaban Z, Shirazi MRJ, Nooranizadeh MH, Tamadon A, Rahmanifar $F$ and Ahmadloo S. (2018): Decreased expression of the arginine-phenylalanine-amide-related peptide-3 gene in dorsomedial hypothalamic nucleus of constant light exposure model of a polycystic ovarian syndrome. Int $\mathbf{J}$ Fertil Steril., 12 (1): 43-50. 
63. Sirmans SM and Pate KA. (2013): Epidemiology, diagnosis and management of polycystic ovary syndrome: Review. Clin Epidemiol., 2014(6): 1-13.

64. Sorour HA, Abdel Aal FS and Abd-Elgalil MM. (2017): Ovarian cytoarchitectural changes following fennel ingestion in senile diabetic albino rat. Egyptian journal of histology, 40 (4): 427-442.

65. Stubert J, Dieterich $M$ and Gerber $B$. (2014): Medical prevention of breast cancer. Breast Care, 9: 391-396.

66. SulaimanA, Farzana FK, Ruckmani A and Vijayalakshmi K. (2015): Effects of flax seeds supplementation in polycystic ovarian syndrome. International Journal of Pharmaceutical Sciences Review and Research, 31(1): 113-119.
67. Sun J, Jin C, Wu H, Zhao J, Cui Y, Liu H, Wu L, Shi Y and Zhu B. (2013): Effects of electro-acupuncture on ovarian P450arom, $\mathrm{P} 450 \mathrm{c} 17 \mathrm{a}$ and mRNA expression induced by letrozole in PCOS rats. PLoS One, 8(11) Suppl. e79382: 1-10.

68. Tahmasebi F, Movahedin $M$ and Mazaheri Z. (2015): Poly Cystic Ovary Model as an Elevated Oxidative Stress Factor. J Mazandaran Univ Med Sci., 25(127): 82-91.

69. Tharwat S, Shaheen D, El-Megeid AA, Salam R, Rashed $L$ and El-Hamid S, Abdel-Shafy S and Shaheen D. (2017): Effectiveness of Adding Flaxseed to Type 2 Diabetic Patient's Regimen. Endocrinol Metab Syndr., 6 (3): 267-271.

70. Xu $H$ and Ren D. (2015): Lysosomal physiology. Annu Rev Physiol., 77:57-80. 
التأثير المحتمل لمستخلص بذور الكتان على نموذج الجرذان

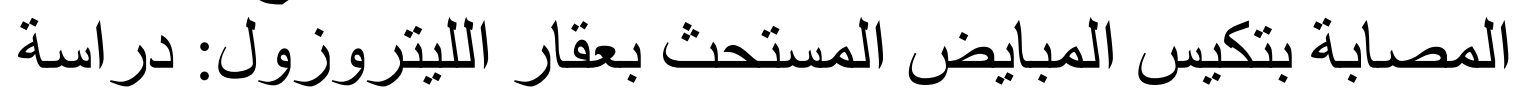
نسيجية ووظيفية منر ابطة منى محمد عبد الجليل**، شيماء فتحي محمد**

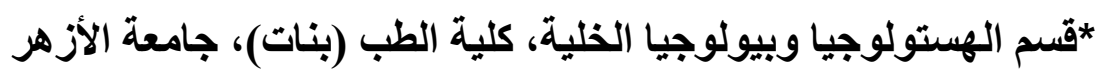

**:قسم الفيسيولوجي، كلية الطب (بنات)، جامعة الأزهر

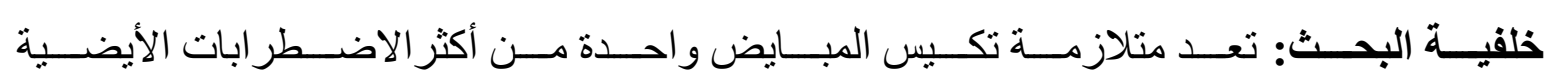

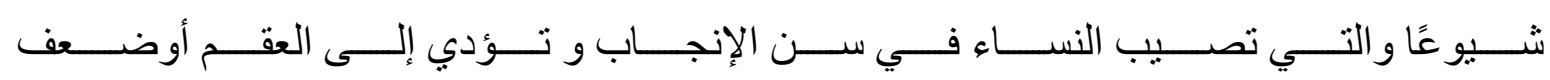

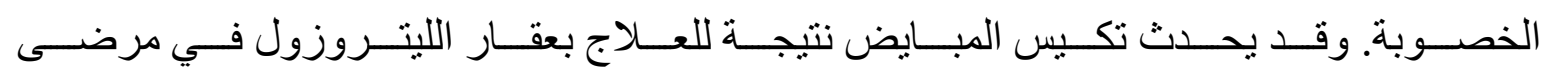

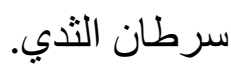

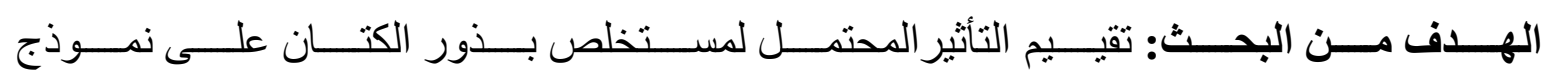
الجرذان الصصابة بتكيس المبايض المستحث بعقار اللبتروزول.

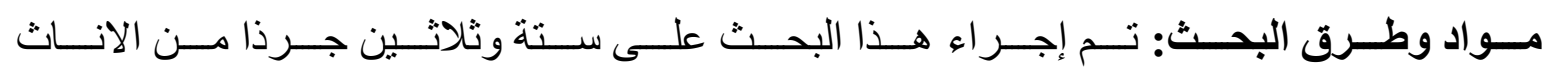
البيضاء البالغة و النى تم تقسيمهم الى خمس مجمو عات رئيسية:

المجموعة الأولى: المجمو عة الضابطة.

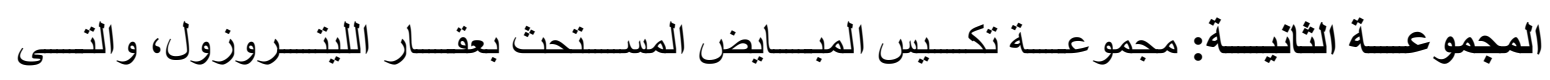

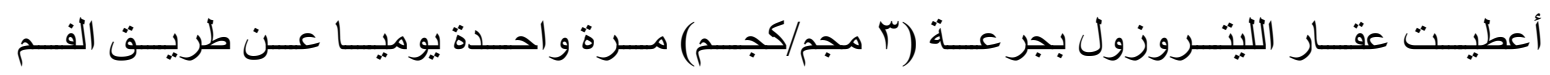
بواسطة أنبوب معدي لمدة الب يوما.

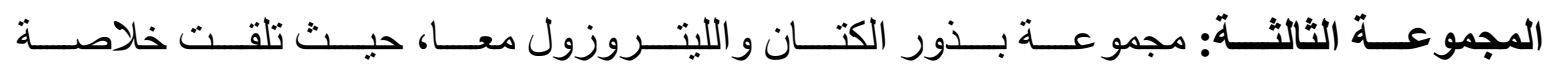

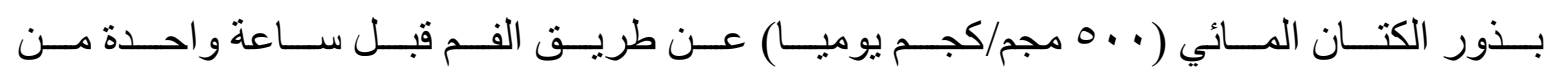
تناول عقار الليتروزول بنفس الجرعة و المدة مثل المجموعة الثانية.

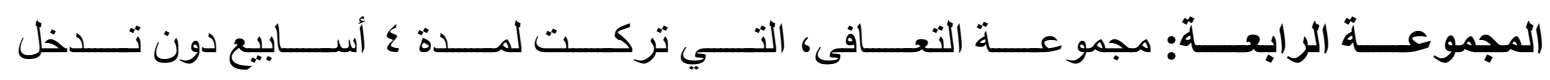
علاجي بعد إستحداث تكيس المبايض بعقار اليتروزول. 
THE POSSIBLE EFFECT OF FLAXSEED EXTRACT ON LETROZOLE-... 3095

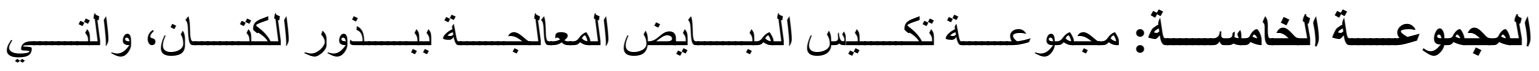

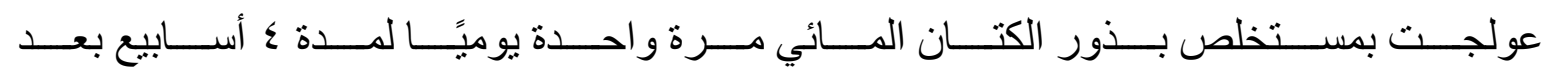
إستحداث تكبس المبايض بعقار الليتروزول.

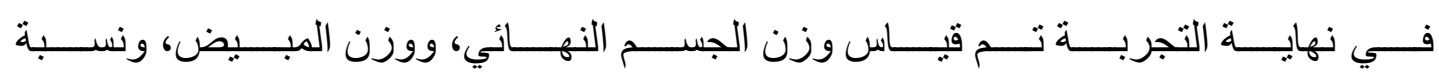

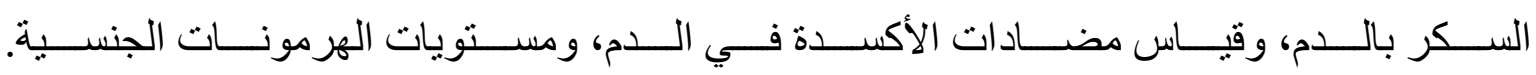

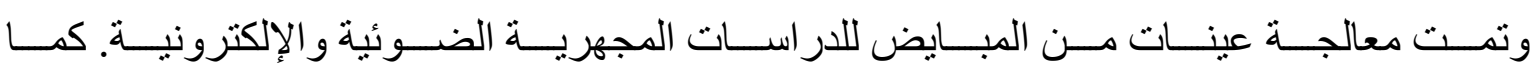
أجريت التحليلات النسيجية والإحصائية.

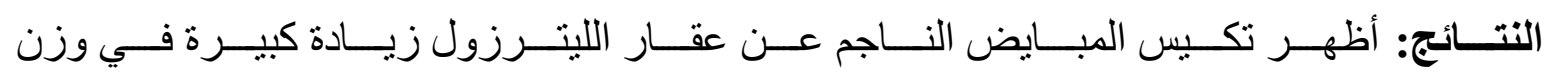

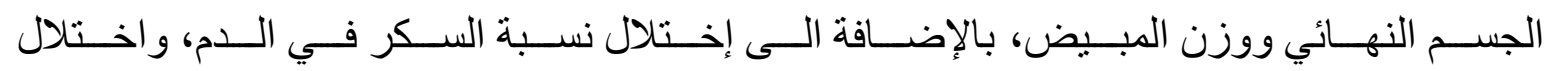

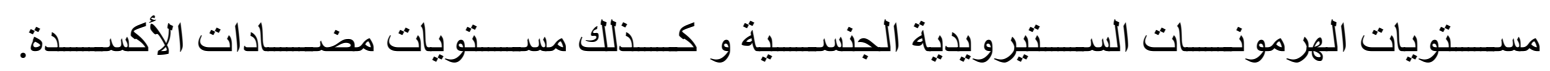

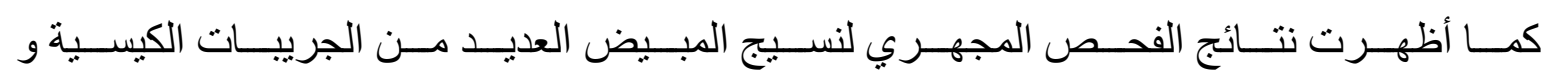

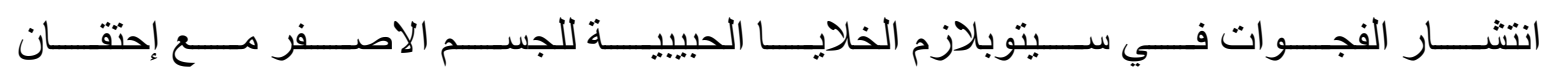

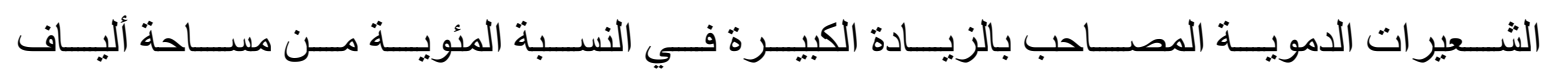

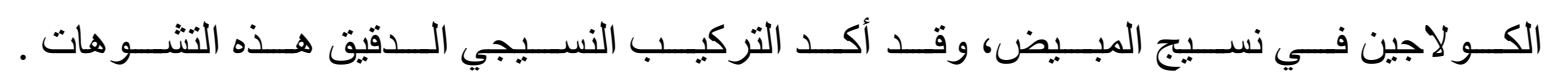

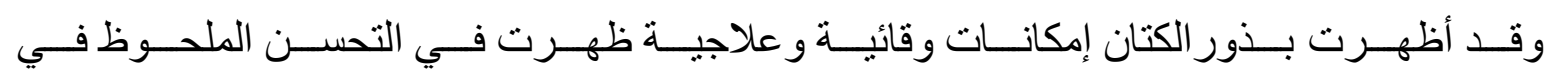

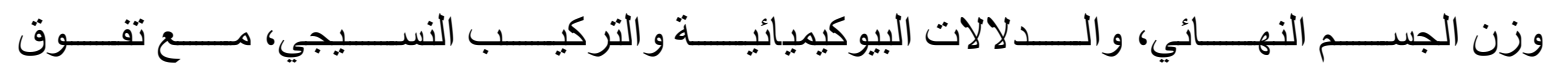
التأثثر الوقائي على التأثير العلاجي.

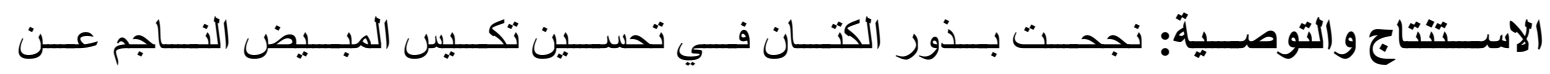

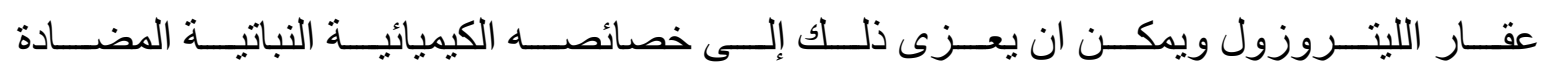

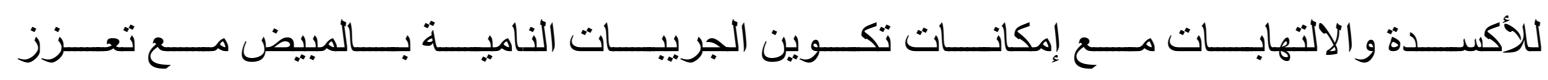

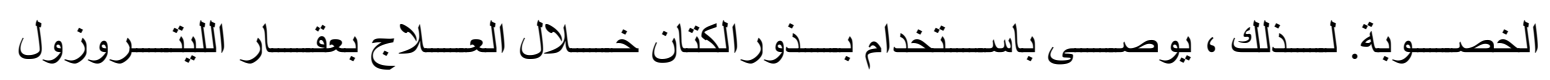
للحد من آثاره الناجمة عن زيادة مستويات الأندروجين. 